\title{
Estimating incentive and welfare effects of non-stationary unemployment benefits
}

\author{
Andrey Launov ${ }^{(a, b)}$, Irene Schumm ${ }^{(a)}$ and Klaus Wälde ${ }^{(b, c), 1}$ \\ ${ }^{(a)}$ University of Würzburg, ${ }^{(b)}$ UC Louvain-la-Neuve \\ (c) University of Glasgow and CESifo
}

January 22, 2009

work in progress

\begin{abstract}
We formulate a general equilibrium matching model with spell-dependent unemployment benefits and endogenous search effort. The model gives rise to an endogenous distribution of unemployment duration characterized by a time-varying hazard function. Using methods from the literature on Semi-Markov processes, we obtain an expression for the aggregate unemployment rate under heterogeneous search effort. We perform structural estimation of the model using a German micro-data set (SOEP) and discuss the effects of the recent unemployment benefit reform (Hartz IV). Our results show that although the reform and economic growth have contributed to the reduction of the aggregate unemployment rate, aggregate welfare has gone down.
\end{abstract}

JEL Codes: J 65, J 64, C 13

Keywords: Non-stationary unemployment benefits, general equilibrium matching model, structural estimation, Semi-Markov process

\section{Introduction}

Continental European unemployment is notorious for its persistence. France, Italy and Germany have had rising unemployment rates from the 1960s up to 2000 and even onward. There seems to be a consensus now that a combination of shocks and institutional arrangements lies at the origin of these high unemployment rates (Ljungqvist and Sargent, 1998, 2007a, b; Mortensen and Pissarides, 1999; Blanchard and Wolfers, 2000). Neither institutions nor shocks alone explain the rise in unemployment: institutions have always been there but unemployment has not (at least not at this level) and shocks have hit many countries but not all countries have high unemployment rates. The step from this shock-institutions insight towards finding a solution to the European unemployment problem seems to be short: As

\footnotetext{
${ }^{1}$ Contact details: Andrey Launov, Université catholique de Louvain à Louvain-La-Neuve, Place Montesquieu 3, 1348 Louvain-La-Neuve, Belgium, Phone: +32.10.47-4141, andrey.launov@uni-wuerzburg.de. Irene Schumm, University of Wuerzburg, Lehrstuhl fuer VWL II, Sandering 2, 97070 Wuerzburg, Phone: +49.931.31-2952, irene.schumm@uni-wuerzburg.de. Klaus Wälde, University of Glasgow, Department of Economics, Glasgow G12 8RT, Scotland, Phone: +44.141.330-2446, klaus@waelde.com, www.waelde.com.
} 
shocks will not go, we need to address the institutions. A common suggestion is to reduce long and generous unemployment benefits.

Is this advisable? Should one reduce the length and level of unemployment benefits in order to reduce unemployment? Finding an answer makes one face a classic efficiency-equity trade-off. While reducing unemployment per se is beneficial, income of the unemployed and the insurance mechanism implicit in unemployment benefits should not be neglected.

We examine qualitatively and quantitatively the employment and welfare effects of a policy reform which reduces the length and level of unemployment benefits. We use Germany as an example of a continental European country, as the so-called "Hartz IV reform" implemented in January 2005 comprises both the reduction of benefits and the cut of the duration of entitlement and because the German unemployment benefit system has a typical two-tier structure as in many other OECD countries. Unemployment insurance (UI) payments before the reform were paid for a period of 6 to 32 months followed by unemployment assistance (UA) payments, the latter potentially lasting up to infinity. The experience of Germany with rising unemployment rates over decades is shared by many other countries and, similarly to Germany in 2005, many countries did reduce length and level of unemployment payments in order to address the issue of high and persistent unemployment (OECD, 2004).

The Hartz IV reform has introduced two main modifications. First, the UA payments, formerly proportional to net earnings before the job loss, were replaced by a uniform benefit level. The effect of this new rule on the income of long-term unemployed workers was ambiguous. There were unemployed whose benefit payments were lower before 2005 than after the reform, mainly unemployed workers from the low wage sector. Those were the "winners" of the reform (47 percent of long-term unemployed). On the other hand, there were also long-term unemployed with relatively high wages before entering unemployment. These were affected negatively by the new law and their income has dropped (53 percent of long-term unemployed). Despite the fraction of "winners" and "losers" is roughly equal, the gain of the winners has turned out to be lower than the loss of the losers leading to a loss of the average worker of a bit more than $7 \%$ due to Hartz IV (Blos and Rudolph, 2005; OECD, 2007). Second, for workers who entered unemployment from February 2006 onward, the maximum duration of entitlement to unemployment insurance payments was reduced to 12 months (formerly, 15 months was the average).

At first sight, the reforms seem to have worked. The reported unemployment rate dropped between January 2005 and January 2007 from $12.3 \%$ to $10.2 \%$. On the other hand, growth rates in Germany were (for German standards) fairly high. While the German economy shrank in 2003, it has recovered since then and probably also created new jobs. The real GDP grew by 0.8 percent in 2005 and by 2.9 percent in 2006 . Given this background, we are left with at least three questions: Did the reform reduce unemployment and increase output? (Yes.) Did it increase welfare of the unemployed and/or employed workers? (No.) Does it increase social welfare or expected utility? (No.) In short, our findings suggest that post-reform unemployment benefits reduced the insurance mechanism of UA payments too much and overemphasized the incentive effect. ${ }^{2}$

We reach our conclusions by using a model which combines various strands of the litera-

\footnotetext{
${ }^{2}$ This does not mean that labour market institutions should not be reformed. It rather means that one should look for Pareto-improving reforms (e.g. introducing progressive social security payments).
} 
ture and adds some new and essential features. We employ a general equilibrium matching framework and extend the standard text-book model for time-dependent unemployment benefits, endogenous effort, risk-averse households, an exogenous "spell-effect" and Semi-Markov tools. Each of these extensions is crucial. Unemployment benefits in our model need to depend on the length of the unemployment spell as this is a feature of basically all OECD unemployment benefit systems. Letting agents optimally choose their effort to find a job, we can analyze the incentive effects of (reforms of) the unemployment benefit system on the search intensity. Risk-averse households are required as we also want to evaluate insurance effects. The spell-effect allows us to obtain - depending on how fast it sets in - rising, falling or hump-shaped exit rates. Finally, tools from the Semi-Markov literature are required as this allows us to deduce the aggregate unemployment rate from individual search. We can thereby compute macro efficiency effects resulting from micro incentives.

We solve this model numerically by looking at Bellman equations as differential equations. This gives us solutions which are as accurate as numerical precision and which do not require us to approximate the model in any way. Optimal behaviour implies an exit rate into employment which is a function of the time spent in unemployment. We thereby obtain a flexible enough endogenous distribution of unemployment duration which we employ for structural estimation of model parameters. Estimation by maximum likelihood is then (relatively) straightforward.

The main theoretical contribution of our analysis is the explicit treatment of the SemiMarkov nature of optimal individual behaviour due to the presence of spell-dependent unemployment benefits: Optimal exit rates not only depend on whether the individual is unemployed (the current state of the worker) but also on how long an individual has been unemployed. While this Semi-Markov aspect has been known for a while, it has not been fully exploited so far in the search literature. Using results from the applied mathematics literature, we obtain analytic expressions for individual employment probabilities contingent on current employment status and duration of unemployment. They allow us to compute aggregate unemployment rates using a law of large numbers in our pure idiosyncratic risk economy. Given this link from optimal individual behaviour to aggregate outcomes, we can analyze the distribution and efficiency effects of changes in level and length of unemployment benefits.

The main empirical contribution is the careful modelling of exit rates into employment. Individual incentives due to falling unemployment benefits imply more search effort and therefore higher exit rates over time. Empirical evidence shows, however, that exit rates tend to fall - at least after some initial increase over the first 3-4 months of unemployment. We therefore combine individual incentive effects with an exogenous time-decreasing spelleffect and with unobserved heterogeneity. As is well known, the latter implies inter alia falling aggregate exit rates even though individual exit rates are rising. Structural estimation then establishes the importance of the time-effect and the unobserved heterogeneity effect. We find that the model can replicate empirical stylized facts of first rising and then falling exit rates.

The main policy contribution is our emphasis and structural estimation of the tradeoff between insurance and incentive effects of labour market policies. The degree of riskaversion - crucial for understanding the insurance effect - is jointly estimated with exit rates and the spell-effect (and other model parameters). A comparative static analysis using the 
estimated version of the theoretical model then allows us to derive precise predictions about the employment and distribution effects of changes in the length and level of unemployment benefits.

Our paper is related to various strands in the literature. From a theoretical perspective, we build on the search and matching framework of Diamond (1982), Mortensen (1982) and Pissarides (1985), recently surveyed by Rogerson et al. (2005). Time-dependent unemployment benefits and endogenous effort have been originally analyzed by Mortensen (1977) in a one-sided job search model. Equilibrium search and matching models include Cahuc and Lehman (2000), Fredriksson and Holmlund (2001). ${ }^{3}$ These models, however, are less powerful than our model in explaining the anticipation effect of the reduction in benefits, as exit rates within each benefit regime are constant. There also exists a substantial literature that studies optimal insurance allowing for an arbitrary time path of unemployment benefit payments (Shavell and Weiss, 1979; Hopenhayn and Nicolini, 1997; Shimer and Werning, 2007). Our focus is more of a positive nature trying to understand the welfare effects of existing systems which have a simpler benefit structure than the ones resulting from an optimization approach. We also allow for an unlimited number of transitions between employment and unemployment and undertake a general equilibrium analysis as in Moscarini (2005). ${ }^{4}$

From an empirical perspective, we estimate a parametric duration model (Lancaster, 1990) in which time dependence of the hazard function due to time-dependent benefits is fully described by the equilibrium solution of our theoretical model. Econometric models with time-dependent benefits were originally estimated by van den Berg (1990) and Ferrall (1997). ${ }^{5}$ Van den Berg et al. (2004) and Abbring et al. (2005) extend the setting by introducing time dependence due to monitoring and sanctions. In contrast to our model, this literature deals with one-sided job search, which makes application of its estimates in a general equilibrium analysis rather difficult. In addition to that, focus on the incentive effect in is only partial (van den Berg et al., 2004; Abbring et al., 2005) and insurance effect remains largely unaddressed. There also exists a larger empirical equilibrium search literature that deals with unemployment benefit heterogeneity (Bontemps et al., 1999), heterogeneity in workers abilities (Postel-Vinay and Robin, 2002) and heterogeneity in workers value of nonparticipation (Flinn, 2006). Unlike in our model, however, neither of these contributions views heterogeneity as being a result of time-dependence.

Finally, Semi-Markov methods are taken from the applied mathematical literature, see e.g. Kulkarni (1995) or Corradi et al. (2004).

The structure of our paper is as follows. In section 2 we present the theoretical model, institutional setting, behaviour of supply and demand sides and the combination of both in economic welfare. Section 3 describes the equilibrium properties of the model. Section 4 illustrates the structural estimation and the underlying data. The simulation results and the

\footnotetext{
${ }^{3}$ Albrecht and Vroman (2005) and Coles and Masters (2007) also have time-dependent unemployment payments but they do not analyze the implications for individual effort. Albrecht and Vroman focus on the equilibrium wage dispersion and inefficient job rejection. Coles and Masters model aggregate uncertainty implying implicit transfers between firms and the stabilizing effect this has on the unemployment rate over the cycle.

${ }^{4}$ Acemoglu and Shimer (1999) do consider a general equilibrium model, but their setting is restricted to time-invariant benefits only.

${ }^{5}$ See also Eckstein and van den Berg (2007) for literature review on nonstationary empirical models.
} 
evaluation of the institutions reforms are presented in section 5. Section 6 concludes.

\section{The model}

We use a Diamond-Mortensen-Pissarides type matching model and extend it for timedependent unemployment benefits, endogenous effort, risk-averse households and an exogenous spell-effect. To solve it, we use Semi-Markov tools. The separation rate for jobs is constant and there is no search on the job. We focus on steady states in our analysis. Households are ex-ante identical but endogenously heterogenous in their unemployment duration.

\subsection{Production, employment and labour income}

The economy has a work force of exogenous constant size $N$. Employment is endogenous and given by $L$ and the number of unemployed amounts to $N-L$. Firms produce under perfect competition on the goods market and each worker-firm match produces output $A$, which is constant. The production process of the worker and the firm can be interrupted by exogenous causes which occur according to a time-homogenous Poisson process with a constant arrival rate $\lambda$.

Unemployed workers receive UI benefits $b_{1}$ and UA benefits $b_{2}$. Benefits are modelled to reflect institutional arrangements in many European countries. One of the most important features is the dependence of UI benefits on the unemployment spell. Empirical work has repeatedly shown (Moffitt and Nicholson, 1982; Blanchard and Wolfers, 2000) that the length of entitlement to unemployment insurance payments plays a crucial role in determining the unemployment rate. Workers with a spell $s$ shorter than $\bar{s}$ (say one year) receive UI benefits $b_{1}$, afterwards, they receive $b_{2}$,

$$
b(s)=\left\{\begin{array}{ll}
b_{1} & 0 \leq s \leq \bar{s} \\
b_{2} & \bar{s}<s
\end{array} .\right.
$$

We assume $b_{1}>b_{2} \geq 0$. Benefits can be paid either at a fixed level or proportional to previous income.

An unemployed worker finds a job according to a time - inhomogenous Poisson process with arrival rate $\mu($.$) . This rate will also be called the job-finding rate, hazard rate or exit$ rate (into employment). We allow this rate to depend on effort $\phi(s(t))$ an individual exerts to find a job. Effort today in $t$ depends on the length $s(t)$ this individual has been spending in unemployment since his last job. The spell increases linearly in time and starts in $t_{0}$ where the individual has lost the job, i.e. $s(t)=t-t_{0}$. An individual whose duration of unemployment spell $s(t)$ exceeds the length of entitlement to UI benefits $\bar{s}$ (i.e. $s(t) \geq t_{0}+\bar{s}$ ) will be called a long-term unemployed.

In addition to effort, the exit rate of an individual will also depend on aggregate labour market conditions and on something which, for simplicity, we call a spell-effect. Labour market conditions are captured by labour market tightness $\theta$ that differs across steady states, $\theta \equiv V / U$. We assume that effort and tightness are multiplicative: no effort implies permanent unemployment and no vacancies imply that any effort is in vain. The spell-effect captures 
all factors exogenous to the individual which affects her exit rate into employment. This can include stigma, ranking (Blanchard and Diamond, 1994) and gains or losses in individual search productivity. We denote this effect by $\eta(s)$. Assuming that a stigma becomes worse the longer $s$, we would expect $\eta(s)$ to fall in $s$. Summarizing, the exit rate will be of the form $\mu(\phi(s(t)) \theta, \eta(s))$.

There is a long discussion in the literature whether aggregate falling exit rates are due to a time effect (as modeled here by $\eta(s)$ ) or due to unobserved heterogeneity (Kiefer and Neumann, 1981, Flinn and Heckman, 1982 and, non-parametrically, Heckman and Singer, 1984, van den Berg and van Ours, 1996). We take unobserved heterogeneity into account in our empirical part and discuss its effects there.

The outcome of our time-varying exit rate will be an endogenous distribution of unemployment duration. Its density is given by (e.g. Ross, 1996, ch. 2)

$$
f(s)=\mu(\phi(s) \theta, \eta(s)) e^{-\int_{0}^{s} \mu(\phi(u) \theta, \eta(u)) d u} .
$$

This density will be crucial later for various purposes including the estimation of model parameters. It is endogenous to the model, as exit rate $\mu(\phi(s(t)) \theta, \eta(s))$ follows from the optimizing behaviour of workers and firms. ${ }^{6}$

Unemployment benefit payments to short- and long-term unemployed are financed by a tax rate $\kappa$ on gross wages such that the net wage is $w=(1-\kappa) w^{\text {gross }}$. The budget constraint of the government therefore reads

$$
\left(b_{1} \int_{0}^{\bar{s}} f(s) d s+b_{2} \int_{\bar{s}}^{\infty} f(s) d s\right)(N-L)=\kappa \frac{w}{1-\kappa} L
$$

where $\int_{0}^{\bar{s}} f(s) d s(N-L)$ is the number of short term and $\int_{\bar{s}}^{\infty} f(s) d s(N-L)$ is the number of long-term unemployed. The government adjusts the wage tax $\kappa$ such that this holds at each point in time.

The wage is determined by bargaining to which we return below.

\subsection{Optimal behaviour}

- Households

Households are infinitely lived and do not save. The present value of having a job is given by $V(w)$ and depends on the current endogenous wage $w$ only. Employed workers enjoy instantaneous utility $u(w, \psi)$ where $\psi$ captures disutility from working. ${ }^{7}$ The value $V(w)$ is constant in a steady state as the wage is constant, but differs across steady states. Whenever a worker loses his job, he enters the unemployment benefit system by obtaining insurance payments $b_{1}$ for the full length of $\bar{s}$. Workers are immediately granted full benefit entitlements, i.e. unemployment payments are not experience rated. See the bargaining setup for further discussion. Hence, the value of being unemployed when just having lost the

\footnotetext{
${ }^{6}$ Also note that due to drop of benefits at $\bar{s}, f(s)$ will have a more general hurdle structure (see Appendix).

${ }^{7}$ This parameter only serves to contrast search effort of unemployed workers and plays no major role.
} 
job is given by $V\left(b_{1}, 0\right)$ where 0 stands for a spell of length zero. This leads to a Bellman equation for the employed worker of

$$
\rho V(w)=u(w, \psi)+\lambda\left[V\left(b_{1}, 0\right)-V(w)\right] .
$$

The Bellman equation for the unemployed worker reads

$\rho V(b(s), s)=\max _{\phi(s)}\left\{u(b(s), \phi(s))+\frac{d V(b(s), s)}{d s}+\mu(\phi(s) \theta, \eta(s))[V(w)-V(b(s), s)]\right\}$.

The instantaneous utility flow of being unemployed, $\rho V(b(s), s)$, is given by three components. The first component shows the instantaneous utility resulting from consumption of $b(s)$ and effort $\phi(s)$. The second component is a deterministic change of $V(b(s), s)$ as the value of being unemployed changes over time. The third component is a stochastic change that occurs at job-finding rate $\mu(\phi(s) \theta, \eta(s))$. When a job is found, an unemployed gains the difference between the value of being employed $V(w)$ and $V(b(s), s)$.

An optimal choice of effort $\phi(s)$ for (5) requires

$$
u_{\phi(s)}(b(s), \phi(s))+\mu_{\phi(s)}(\phi(s) \theta, \eta(s))[V(w)-V(b(s), s)]=0,
$$

where subscripts denote (partial) derivatives. It states that the expected utility loss resulting from increasing search effort must be equal to expected utility gain due to higher effort.

We require that the value of unemployment an instant before becoming a long-term unemployed is identical to the value of being long-term unemployed at $\bar{s}$, i.e.

$$
V\left(b_{1}, \bar{s}\right)=V\left(b_{2}, \bar{s}\right) .
$$

\section{- Firms}

The value of a job $J$ to a firm is given by instantaneous profits $A-w /(1-\kappa)$, which is the difference between revenue $A$ and the gross wage $w /(1-\kappa)$, reduced by the risk of being driven out of business

$$
\rho J=A-w /(1-\kappa)-\lambda J
$$

where $\rho$ stands for the interest rate (being identical to the discount rate of households) and where we anticipate that the value of a vacancy is zero.

Given that individual arrival rates are a functions of the individual unemployment spell, the expected rate of exit out of unemployment is just the mean over individual arrival rates, given the endogenous distribution of the unemployment spell $f(s)$ from (2),

$$
\bar{\mu}=\int_{0}^{\infty} \mu(\phi(s) \theta, \eta(s)) f(s) d s .
$$

As a consequence, the vacancy filling rate is $\theta^{-1} \bar{\mu}$. The value of a vacant job is $\rho J_{0}=$ $-\gamma+\theta^{-1} \bar{\mu}\left[J-J_{0}\right]$. With free entry, the value of holding a vacancy is $J_{0}=0$, leading to

$$
J=\gamma \theta / \bar{\mu} .
$$


- Wages

We let wages be determined by Nash bargaining. We assume that the outcome of the bargaining process is such that workers receive a share $\beta$ of the total surplus of a successful match $V(w)-V\left(b_{1}, 0\right)=\beta\left[J\left(\frac{w}{1-\kappa}\right)-J_{0}+V(w)-V\left(b_{1}, 0\right)\right]$. The total surplus is the gain of the firm plus the gain of the worker from the match where the latter depends crucially on the outside option of the worker. The fact that we use $V\left(b_{1}, 0\right)$ as the outside option of the worker means that all workers (even if only working for an instant or, in the limit, if only bargaining) are entitled to full unemployment benefits, i.e. $b_{1}$ over the full length $\bar{s}$ and $b_{2}$ for $s>\bar{s} .^{8}$ An alternative would consist in specifying $V(b(s), s)$ as the outside option: if the bargain fails, the unemployed worker remains unemployed and continues to receive benefits she received before the unsuccessful bargaining. This would be theoretically interesting as an endogenous wage distribution would arise (see Albrecht and Vroman, 2005) where the distinguishing determinant across workers is the previous unemployment spell. Using an identical outside option for all individuals, however, has the advantage that all workers are homogenous. Once an unemployed finds a job, all history is deleted, all workers are the same and, independently of their employment history, earn the same wage. ${ }^{9}$

Following the steps as in Pissarides (1985), we end up with a generalized wage equation that reads (see app. B.7)

$$
(1-\beta) u(w, \psi)+\beta \frac{w}{1-\kappa}=(1-\beta) u\left(b_{1}, \phi(0)\right)+\beta[A+\theta \gamma] .
$$

The left hand side corresponds to what in models with risk-neutrality and without taxation is simply the wage rate. If we had $\kappa=0$ and $u(w, \psi)=w-\psi$, we would obtain just $w$ on the left and additionally $(1-\beta) \psi$ on the right. Consequently, the worker is not only compensated for the outside option in the case of unemployment $u\left(b_{1}, \phi(0)\right)$ but also for the disutility resulting from work $\psi$. The tax rate, that appears as the term $w /(1-\kappa)$, results from the instantaneous profit of a firm (8) which needs to pay a gross wage of $w /(1-\kappa)$. The right hand side is a simple generalization of the standard wage equation of Pissarides (1985). Instead of benefits for the unemployed (which we would find on the right for riskneutral households and no time-dependence of effort), we have instantaneous utility from being unemployed. The impact of the production side is unchanged when compared to the standard wage equation.

Instead of specifying the outside option differently, one could also allow for strategic bargaining. Many recent papers have used strategic bargaining given that either payoffs change over time and Nash bargaining would correspond to myopic behaviour (Coles and Wright, 1998; Coles and Muthoo, 2003), that a careful analysis of on-the-job search makes strategic bargaining more appropriate (Cahuc, Postel-Vinay and Robin, 2006) or that unemployment does not have such a strong effect on bargaining as generally thought (Hall and Milgrom,

\footnotetext{
${ }^{8}$ In the quantitative part, the "full length" $\bar{s}$ will be provided by the data. In this sense, entitlement is taken into account.

${ }^{9}$ Our assumption that all workers, even if they have worked only for a second, are entitled to $b_{1}$ for the full period of length $\bar{s}$ is identical to saying that benefit payments are not experience rated. While the absence of experience rating is generally distorting the firms decision to lay off workers (see e.g. Mongrain and Roberts, 2005), this does not play a role in our setup as the separation rate is exogenous. It would be interesting to study the impact of endogenous separation decisions but we leave this for future research.
} 
2008). ${ }^{10}$ Brügemann and Moscarini (2007) find (for a different question) that the quantitative differences between different wage-setting rules are small. Given that we want to focus here on the direct incentive effects of non-stationary unemployment benefits on search effort, we feel justified to "switch off" the strategic channel and leave this for future work.

\subsection{Welfare}

When we evaluate unemployment policies, we take all agents in our economy into account. There are workers with value $V(w)$, the unemployed with value $V(b(s), s)$ depending on their spell $s$ and firms with value $J$. When we compare one policy to another, we look at total output (i.e. employment), distributional effects and overall welfare. We obtain a social welfare function $\Omega$ by aggregating - in spirit as in Hosios (1990) or Flinn (2006) - over all these welfare levels in a standard Bentham-type utilitarian way, ${ }^{11}$

$$
\Omega=L[V(w)+J]+(N-L)\left(\int_{0}^{\bar{s}} V\left(b_{1}, s\right) f(s) d s+\int_{\bar{s}}^{\infty} V\left(b_{2}, s\right) f(s) d s\right) .
$$

Social welfare is given by the number $L$ of employed workers/ firms times their welfare plus the number of unemployed workers $N-L$ times the average welfare of an unemployed. This average is obtained by integrating over all spells $s$, where $f(s)$ is the endogenous density (2), with exit rates $\mu(\phi(s) \theta, \eta(s))$ that follow from the steady state solution of the model, and the $V\left(b_{i}, s\right)$ are the values of being unemployed with a spell $s$ and benefit payments $b_{i}$ from (1).

\section{Equilibrium properties}

\subsection{Individual (un)employment probabilities}

In models with constant job-finding and separation rates, the unemployment rate can easily be derived by assuming that a law of large numbers holds. Aggregate employment dynamics can then be described by $\dot{L}=\mu[N-L]-\lambda L$ which allows to compute unemployment rates. With spell-dependent effort, individual arrival rates $\mu($.$) are heterogeneous and employment$ dynamics need to be derived using techniques from the literature on Semi-Markov or renewal processes, e.g. Kulkarni (1995) or Corradi et al. (2004).

The generalization of Semi-Markov processes compared to continuous time Markov chains consists in allowing the transition rate from one state to another to depend on the time an individual has spent in the current state. We apply this here and let the transition rate from unemployment to employment depend on the time $s$ the individual has been unemployed. Hence, switching from a constant job-finding rate $\mu$ to a spell-dependent rate $\mu(s)$ implies switching from Markov to Semi-Markov processes. Processes are called "semi" as the historydependence of the job finding rate $\mu(s)$ is not Markov. Processes are still called "Markov" as

\footnotetext{
${ }^{10}$ Coles and Masters (2004) analyse wage setting by strategic bargaining in a matching setup with nonstationary unemployment benefits. They do not consider endogenous search intensity, however.

${ }^{11}$ Dividing by $N$ gives expected utility of a worker "thrown into" this economy from behind some "veil of ignorance". Higher social welfare is therefore identical to higher expected utility. One could therefore equilvalently ask in which economy such a worker would like to land.
} 
once an individual has found a job, history no longer counts. This is also why these processes are called renewal processes: whenever a transition to a new state occurs, the system starts from the scratch, it is "renewed" and history vanishes.

We start by looking at individual employment probabilities. Let $p_{i j}(\tau, s(t))$ describe the probability with which an individual, who is in state $i$ (either $e$ for employed or $u$ for unemployed) today in $t$, will be in state $j \in\{e, u\}$ at some future point in time $\tau$, given that his current spell is now $s(t)$. These expressions read, starting with $s(t)=0$ and taking into account that the separation rate $\lambda$ remains constant (see app. A.3),

$$
\begin{aligned}
p_{u u}(\tau, 0) & =e^{-\int_{t}^{\tau} \mu(s(y)) d y}+\int_{t}^{\tau} e^{-\int_{t}^{v} \mu(s(y)) d y} \mu(s(v)) p_{\text {eu }}(\tau-v) d v \\
p_{\text {eu }}(\tau) & =\int_{t}^{\tau} e^{-\lambda[v-t]} \lambda p_{u u}(\tau-v, 0) d v
\end{aligned}
$$

Expressions for complementary transitions are given by $p_{u e}(\tau)=1-p_{u u}(\tau)$ and $p_{e e}(\tau)=$ $1-p_{\text {eu }}(\tau)$, respectively.

These equations have a straightforward intuitive meaning. Consider first the case of $\tau$ being not very far in the future. Then all integrals (for $\tau=t$ ) are zero and the probability of being unemployed at $\tau$ is, if unemployed at $t$, one from (13a) and, if employed at $t$, zero from (13b). For a $\tau>t$, the part $e^{-\int_{t}^{\tau} \mu(s(y)) d y}$ in (13a) gives the probability of remaining in unemployment for the entire period from $t$ to $\tau$. An individual unemployed today can also be unemployed in the future if he remains unemployed from $t$ to $v$ (the probability of which is $e^{-\int_{t}^{v} \mu(s(y)) d y}$ ), finds the job in $v$ (which requires multiplication with the exit rate $\mu(s(v))$ ) and then moves from employment to unemployment again over the remaining interval $\tau-v$ (for which the probability is $p_{e u}(\tau-v)$ ). As this path is possible for any $v$ between $t$ and $\tau$, the densities for these paths are integrated. The sum of the probability of remaining unemployed all of the time and of finding a job at some $v$ but being unemployed again at $\tau$ gives then the overall probability $p_{u u}(\tau, 0)$ of having no job in $\tau$ when having no job in $t$. Note that there can be an arbitrary number of transitions in and out of employment between $v$ and $\tau$. The interpretation of (13b) is similar. The probability of remaining employed from $t$ to $v$ is simpler, $e^{-\lambda[v-t]}$, as the separation rate $\lambda$ is constant.

As we can see, these equations are interdependent: The equation for $p_{u u}(\tau)$ depends on $p_{e u}(\tau-v)$ and the equation for $p_{e u}(\tau)$, in turn, depends on $p_{u u}(\tau-v)$. Formally speaking, these equations are integral equations, sometimes called Volterra equations of the first type (13b) and of the second type (13a). Integral equations can sometimes be transformed into differential equations, which will simplify their solution in practice. In our case, however, no transformation into differential equations is known.

After having computed the probability of being unemployed in $\tau$ when being unemployed in $t$ for individuals that just became unemployed in $t$, i.e. who have a spell of length $s(t)=0$, we will need an expression for $p_{u u}(\tau, s(t))$. This means, we will need the transition probabilities for individuals with an arbitrary spell $s(t)$ of unemployment. Luckily, given the results from (13a and b), this probability is straightforwardly given by

$$
p_{u u}(\tau, s(t))=e^{-\int_{t}^{\tau} \mu(s(y)) d y}+\int_{t}^{\tau} e^{-\int_{t}^{v} \mu(s(y)) d y} \mu(s(v)) p_{\text {eu }}(\tau-v) d v .
$$


An unemployed with spell $s(t)$ in $t$ has different exit rates $\mu(s(y))$ which, however, are known from our analysis of optimal behaviour at the individual level. Hence, only the integrals in (14) are different, the probabilities $p_{e u}(\tau-v)$ can be taken from the solution of (13a and b).

\subsection{Aggregate unemployment}

Given our finding in (13) and (14) on $p_{e u}(\tau)$ and $p_{u u}(\tau, s(t))$, we can now compute the expected number of unemployed for any distribution of spell $F(s)$,

$$
E_{t}\left[N-L_{\tau}\right]=\left[N-L_{t}\right] \int_{0}^{\infty} p_{u u}(\tau, s(t)) d F(s(t))+p_{e u}(\tau) L_{t} .
$$

Starting at the end of this equation, given there are $L_{t}$ employed workers in $t$, the expected number of unemployed workers at some future point $\tau$ out of the group of those currently employed in $t$ is given by $p_{e u}(\tau) L_{t}$. Again, one should keep in mind that the probability $p_{\text {eu }}(\tau)$ allows for an arbitrary number of switches between employment and unemployment between $t$ and $\tau$, i.e. it takes the permanent turnover into account.

For the unemployed, we compute the mean over all probabilities of being unemployed in the future, if unemployed today, by integrating over $p_{u u}(\tau, s(t))$ given the current distribution $F(s(t))$. Multiplying this by the number of unemployed today, $N-L_{t}$, gives us the expected number of unemployed at $\tau$ out of the pool of unemployed in $t$. The sum these two expected quantities gives the expected number of unemployed at some future point $\tau$.

The expected unemployment rate at $\tau$ is simply the expression (15) divided by $N$. When we focus on a steady state, we let $\tau$ approach infinity. In order to obtain a simple expression for the aggregate unemployment rate and to show the link to the textbook expression, we assume a pure idiosyncratic risk model where micro-uncertainty cancels out at the aggregate level. Hence, we assume a law of large numbers holds and the population share of unemployed workers equals the average individual probability of being unemployed. This "removes" the expectations operators, so that (15) for a steady state becomes $N-L$ $=[N-L] \int_{0}^{\infty} p_{u u}(s(t)) d F(s(t))+p_{e u} L$. We have replaced $L_{\tau}=L_{t}$ by the steady state employment level $L$ and the individual probabilities by the steady state expressions $p_{u u}(s(t))$ and $p_{e u}$. The probability $p_{e u}$ is no longer a function of $\tau$ as this probability will not change in steady state, while there will always be a distribution of $p_{u u}(s)$, even in steady state.

Solving for the unemployment rates gives

$$
\frac{U}{N}=\frac{p_{e u}}{p_{e u}+\left[1-\int_{0}^{\infty} p_{u u}(s(t)) d F(s(t))\right]}=\frac{p_{e u}}{p_{e u}+\int_{0}^{\infty} p_{u e}(s(t)) d F(s(t))},
$$

where the second expression is more parsimonious. If we assumed a constant job arrival rate here, we would get $p_{e u}=p_{u u}=\lambda /(\lambda+\mu)$ and $p_{u e}=\mu /(\lambda+\mu)$. Inserting this into our steady state results would yield the standard expression for the unemployment rate, $U / N=\lambda /(\lambda+\mu)$. In our generalized setup, the long-run unemployment rate is given by the ratio of individual probability $p_{e u}$ to be unemployed when employed today divided by this same probability plus $1-\int_{0}^{\infty} p_{u u}(s(t)) d F(s(t))$. 


\subsection{Functional forms and steady state}

For estimation purposes and for the numerical solution, we need functional forms for the instantaneous utility function and for the arrival rate. We assume that the instantaneous utility function of an unemployed worker used e.g. in (5) is

$$
u(b(s), \phi(s))=\frac{b(s)^{1-\sigma}}{1-\sigma}-\phi(s) .
$$

Effort is measured in utility terms. The utility function of an employed worker has the same structure only that consumption is given by $w$ and effort is the constant $\psi$.

The arrival rate of jobs $\mu(\phi(s) \theta, \eta(s))$ is assumed to obey

$$
\mu(\phi(s) \theta, \eta(s))=\eta(s)[\phi(s) \theta]^{\alpha} .
$$

If one interprets $\eta(s)$ as a productivity of search, one can look at the expression for $\mu($.$) like$ at a production function. Input factors are effort $\phi(s)$ and vacancies per unemployed worker $\theta$. With $0<\alpha<1$, inputs have decreasing returns. Effort $\phi(s)$ follows from behaviour of households and labour market tightness $\theta$ is the result of free entry and exit into the creation of vacancies. The spell-effect $\eta(s)$ is an exogenous function of the unemployment spell $s$ and its particular parametric form is explained in the next section.

In a steady state, all aggregate variables are constant and there will be a stationary distribution for unemployment spells. The solution of the steady can most easily be found in two steps. Taking the wage $w$ and labour market tightness $\theta$ as exogenous, one can use expressions related to the unemployed for effort, the value of being unemployed and the value of a job, $\phi(b(s), s), V(b(s), s)$ and $V(w)$. Once these quantities are known, one can use the remaining equations of the model to solve for the wage rate and tightness, $w$ and $\theta$. In doing so, all other endogenous variables (exit rate $\mu(s)$ and the implied density $f(s)$, instantaneous utilities $u($.$) , the tax rate \kappa$, individual employment probabilities $p_{i j}$ and the implied number of short- and long-term unemployed and the unemployment rate $U / N$, the number of vacancies, the value function $J$ for the firm and social welfare $\Omega$ ) are determined as well. ${ }^{12}$

\section{Structural estimation}

\subsection{Exit rates out of unemployment}

Before we estimate the model using the data from the German Socio-Economic Panel (SOEP), we need to specify the functional forms for our time effect $\eta(s)$ from (18). ${ }^{13}$ In order to do so, we consider the distributional aspects of our data on observed unemployment duration. The specification of the time effect $\eta(s)$ needs to be sufficiently flexible to be able to capture these aspects.

\footnotetext{
${ }^{12}$ Appendix A.2 provides an explicit presentation of all equations (which above in the model description are given implicitly) and describes the solution procedure.

${ }^{13}$ For more background on the SOEP and for descriptive statistics, see app. A.1.
} 
The left panel of fig. 1 shows the nonparametric estimate of the hazard function from the entire sample of unemployment durations. The right panel of this figure shows as the solid line the hazard functions for the subsamples of individuals with entitlement length equal to 12 months. The dashed line shows the hazard rate of those nonentitled to unemployment insurance $b_{1} \cdot{ }^{14}$ Both panels plot exit rates for the first 2.5 years of unemployment.
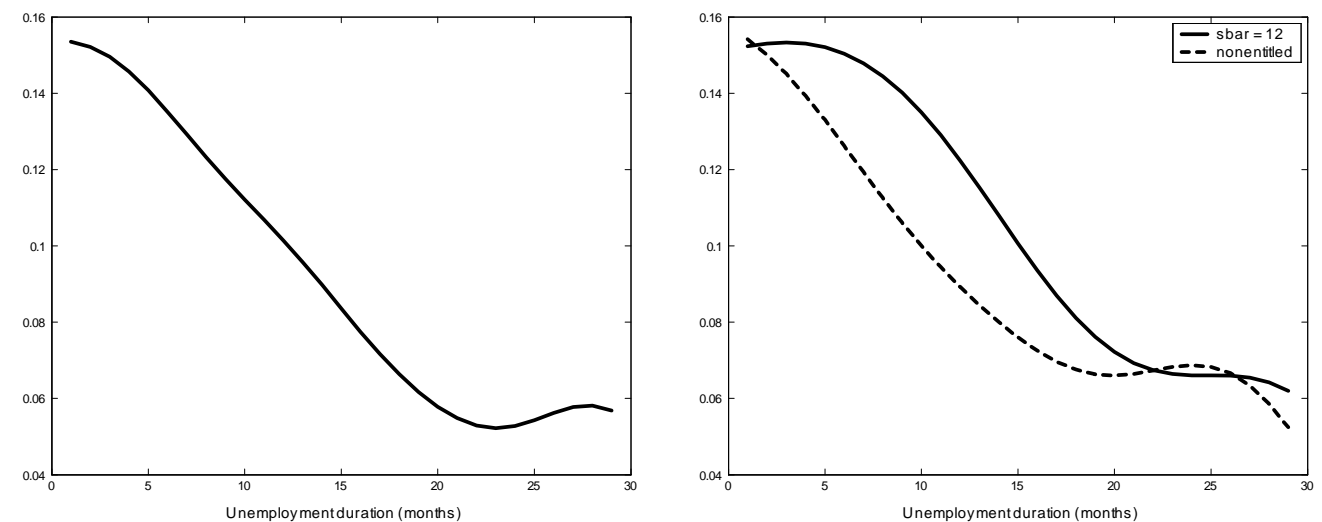

Figure 1 Non-parametric hazard functions (entire sample and $\bar{s}=12$ )

From these figures we can see a clear downward time dependence of the exit risk. On the one hand this may be the evidence of the true downward state dependence of an individual hazard rate (see e.g. van den Berg and van Ours, 1994, or Eckstein and Wolpin, 1995, for the evidence of this). On the other hand, this may be due to unmeasured heterogeneity (Heckman and Singer, 1984; van den Berg and van Ours, 1994). Indeed, as far as Germany is concerned there is at least one source of such unobserved heterogeneity. Namely, all individuals receiving UI benefits may or may not be eligible to UA benefits, once the entitlement period expires. Eligibility to UA benefits is determined at the "means test", where an individual has to provide lengthy information about income sources of the household, number and age of dependents etc. If the means are sufficient, the person becomes ineligible to UA benefits, but might still claim social assistance, which eventually may or may not be provided. Unobservability, in our context, is in the fact that if exit out of unemployment occurs before the expiration of entitlement, an econometrician cannot know about the outcome of the test. The individuals themselves, however, are very likely to know what the result of the test will be. Thus, in case they do not expect to pass the test, they would search harder and therefore exit faster. This behaviour, if uncontrolled for, results in a decreasing nonparametric estimate of the hazard rate. Clearly the true individual exit rate in this particular case may as well be constant, or increasing up to the expiration of entitlement and constant thereafter, as in Mortensen (1977), van den Berg (1991) and also in our theoretical model. Finally, both true individual state dependence and unobserved heterogeneity may manifest themselves simultaneously (see e.g. van den Berg and van Ours, 1994, 1999, for evidence of this in U.S. and French data respectively). ${ }^{15}$

\footnotetext{
${ }^{14}$ See Tanner and Wong (1983) for the definition of the estimator and consistency proof. We use Gaussian kernel. Optimal bandwith is estimated by cross-validation discussed in Tanner and Wong (1984).

${ }^{15}$ Here we also need to note that in what follows we would rather view as a failure at the means test only a situation in which a complete ineligibility to either UA benefits or social assiatnce obtains.
} 
Thus the individual exit rate derived from the theoretical model must have at least two characteristics, namely: a) steady increase before the expiration of entitlement (as in Mortensen, 1977), and b) steady decrease thereafter (as in Heckman and Borjas, 1980). Our theoretical exit rates are broadly consistent with both. When we assume that there is no effect other than that of benefits and tightness, i.e. $\eta(s)$ is constant in (18) due to $\delta_{j}=0$ (no stigma), our model predicts exit rates that increase before $\bar{s}$. If $\delta_{j}$ is very high, exit rates fall over time. For intermediate values of $\delta_{j}$, we get a non-monotonic behaviour and exit rates increase before $\bar{s}$ and fall subsequently, featuring peak at $\bar{s}$. We are therefore confident that our theoretical exit rates are sufficiently flexible for a successful estimation of the model.

Our aim is to provide a fully structural econometric model that estimates the deep parameters of the theoretical model of Section 2 in presence of possible exogenous downward sloping individual state dependence and unobserved heterogeneity.

\subsection{Econometric model}

- Specification

As our data are sampled as a flow of entrants into unemployment and employment, exit rates contain all information necessary for the construction of the likelihood function. The exit rate from our theoretical model is given by (18). The effort level $\phi(s)$ needs to be replaced by the optimal value implied by the first-order condition (6), i.e. $\phi(s)$ is a function of the spell $s$, benefits paid at $s$, the spell-effect $\eta(s)$, the wage $w$ and labour market density $\theta$. To simplify notation, we group these variables into a vector $\mathbf{z} \equiv\left\{b_{1}, b_{2}, \bar{s}, w, \theta\right\}$. As our data set is very rich, there are additional variables of which one can expect that they affect effort and the spell-effect. We group these additional variables in a vector $\mathbf{x}$ that contains the rest of personal characteristics. We assume that these variables affect only the spelleffect and the separation rate, with corresponding parameters $\boldsymbol{\beta}$ and $\boldsymbol{\gamma} \cdot{ }^{16}$ Summarizing, conditional on the vector of observed characteristics, the exit rate from (18) can be written as

$$
\mu_{j}(s)=\mu(\phi(s ; \mathbf{z}) \theta, \eta(s ; \mathbf{x}))=\eta(s ; \mathbf{x})[\phi(s ; \mathbf{z}) \theta]^{\alpha}, \quad j=1,2 .
$$

Effort $\phi(s ; \mathbf{z})$ implies an endogenous individual time dependence due to the anticipation of the benefit reduction and $\eta(s ; \mathbf{x})$ is the exogenous individual time dependence, the spelleffect. Finally, $j$ indicates the benefit regime before $(j=1)$ and after $(j=2)$ expiration of unemployment insurance payments.

We have four type of labour market histories in our dataset. The first group are individuals who enter unemployment with the right to claim UI benefits and exit unemployment before the expiration of entitlement period $(s \leq \bar{s})$. As argued above, for these individuals

\footnotetext{
${ }^{16}$ We are completely aware of the fact that this might appear a strong assumption. It would be desireable to capture this ex ante heterogeneity in the theoretical model right from the beginning. Our objective above, however, was to focus on the implications of a two-tier benefit system under optimal effort with anticipated end date of the first tier. We therefore leave an integration of ex ante heterogeneity with the anticipated two-tier system for future research. It is standard in the literature to model the basic feature of optimal behaviour one is interested in and capture heterogeneity in the econometric part (see e.g. van den Berg and Ridder, 1998 or Flinn, 2006)
} 
we do not observe the outcome of the means test for $b_{2}$. We do assume, however, that individuals know about the outcome even before applying for $b_{2}$. Therefore, let $\phi(s ; \mathbf{z} \mid 0)$ indicate the search effort given that $b_{2}=0$, which corresponds to the hypothetical failure at the test. Similarly, let let $\phi\left(s ; \mathbf{z} \mid b_{2}\right)$ stand for the hypothetical case in which the test will be passed (and so, $b_{2}>0$ ). Finally, let $\boldsymbol{\xi} \equiv\left\{\lambda_{0}, \alpha, \sigma, \eta_{0}, \delta_{j}, \boldsymbol{\beta}, \boldsymbol{\gamma}\right\}_{j=1,2}$ denote the vector of parameters to estimate and let $\pi$ denote the fraction of the individuals that pass the test. Then for a single spell data, the individual contribution of this group is

$$
\begin{aligned}
\ln \ell(\boldsymbol{\xi})= & \ln \left(\pi\left[\mu_{1}\left(s ; \boldsymbol{\xi}, \mathbf{x}, \mathbf{z} \mid b_{2}\right)\right]^{d_{u}} e^{-\int_{0}^{s} \mu_{1}\left(u ; \boldsymbol{\xi}, \mathbf{x}, \mathbf{z} \mid b_{2}\right) d u}\right. \\
& \left.+(1-\pi)\left[\mu_{1}(s ; \boldsymbol{\xi}, \mathbf{x}, \mathbf{z} \mid 0)\right]^{d_{u}} e^{-\int_{0}^{s} \mu_{1}(u ; \boldsymbol{\xi}, \mathbf{x}, \mathbf{z} \mid 0) d u}\right)
\end{aligned}
$$

In this equation and the following, $d_{u}$ is a dummy variable such that $d_{u}=1$ if unemployment spell is uncensored, $d_{t}$ is a dummy variable such that $d_{t}=1$ if we observe that an individual passes the means test, $d_{j}$ is a dummy variable such that $d_{j}=1$ if employment spell is uncensored and $l$ is the employment duration.

Second, consider individuals who enter unemployment with the right to claim UI benefits, fail to find a job before entitlement expires, transit to either UA or zero benefit level and thereby reveal the outcome of the means test, and exit unemployment (or not) only after the expiration of entitlement $(s>\bar{s})$. The densities of these events are given by

$$
\begin{aligned}
\ln \ell(\boldsymbol{\xi})= & d_{t} \ln \pi+\left(1-d_{t}\right) \ln (1-\pi)+d_{u} \ln \mu_{2}(s ; \boldsymbol{\xi}, \mathbf{x}, \mathbf{z}) \\
& -\int_{0}^{\bar{s}} \mu_{1}(u ; \boldsymbol{\xi}, \mathbf{x}, \mathbf{z}) d u-\int_{\bar{s}}^{s} \mu_{2}(u ; \boldsymbol{\xi}, \mathbf{x}, \mathbf{z}) d u
\end{aligned}
$$

For individuals who do not have the right to claim UI benefits and enter unemployment receiving lower UA benefits from the very beginning $\left(d_{t}=1\right)$ or not at all $\left(d_{t}=0\right)$, we have

$$
\ln \ell(\boldsymbol{\xi})=d_{t} \ln \pi+\left(1-d_{t}\right) \ln (1-\pi)+d_{u} \ln \mu_{2}(s ; \boldsymbol{\xi}, \mathbf{x}, \mathbf{z})-\int_{0}^{s} \mu_{2}(u ; \boldsymbol{\xi}, \mathbf{x}, \mathbf{z}) d u .
$$

For our final group, entrants to employment, the log-contribution is

$$
\ln \ell(\boldsymbol{\xi})=d_{j} \ln \lambda(\mathbf{x})-\lambda(\mathbf{x}) l .
$$

Our parametric assumptions about the shape of $\eta(s ; \mathbf{x})$ is

$$
\eta(s ; \mathbf{x})=e^{\mathbf{x}^{\prime} \boldsymbol{\beta}} \eta_{0}\left[e^{-\delta_{1} s^{\delta_{2}}}+1\right]
$$

where $\mathbf{x}$ excludes the constant term. We choose this parametric form for the residual effect is it should cover all the cases of state dependence illustrated in fig. 1 even in the absence of unobserved heterogeneity. Indeed the term in square brackets in (21) spawns a variety of shapes for the hazard function: it can be time-invariant, increasing or decreasing and can also contain one point of inflection, switching from concave to convex shape or vice versa. Thus, even if the influence of unobserved heterogeneity over the outcome of the means test may not be significant, the model will still be flexible enough to replicate the nonparametric estimates. 
For positive $\delta_{i}$, the individual search productivity is $2 e^{\mathbf{x}^{\prime} \boldsymbol{\beta}} \eta_{0}$ at $s=0$ and approaches $e^{\mathbf{x}^{\prime} \boldsymbol{\beta}} \eta_{0}$ for $s$ approaching infinity. ${ }^{17}$

Finally, the conditional rate of exit out of unemployment $\lambda(\mathbf{x})$ has the usual parameterization $\lambda(\mathbf{x})=e^{\mathbf{x}^{\prime} \boldsymbol{\gamma}+\lambda_{0}}$.

- Estimation procedure

Estimation of model parameters uses a part of the numerical solution method for the steady state. As described in app. A.2, for a given wage $w$ and vacancy to unemployment ratio $\theta$, the individual exit rate at any moment of the unemployment spell can be computed. Using individual survey data implies that the wage $w$ for each individual is known and the corresponding $\theta$ can be taken from macro data. Individual exit rates can therefore be computed for each individual job market history in our dataset, given an initial guess for the model parameters. This guess consists of values for $\boldsymbol{\xi}$ plus exogenous values for $\rho$ (0.003, corresponding to an annual interest rate of $3.7 \%)$ and $\beta(0.5)$. The sum of all $\log -$ contributions is then maximized by varying parameters in $\boldsymbol{\xi}$. Details on the implementation can be found in app. B.5.

Note that $\boldsymbol{\xi}$ is estimated without explicitly specifying the wage setting mechanism. If we used linked employer-employee data, the model could be estimated by using the observable productivity data. This would also allow us to estimate the bargaining power parameter $\beta$ as well as provide more information on the discrepancy between the observed wage and an endogenous wage solution implied by the model. For the rest of the parameters unrelated to wage setting mechanism, however, both approaches must be equivalent (assuming that wage setting in the second one is correctly specified). Further, computing the steady state solution suggests that estimation with given wage and tightness is faster by a factor of about 4 .

- Identification

Altogether, the econometric model described in (20a)-(20c) covers three conceptual features of the observed unemployment duration data: (i) endogenous time dependence of the hazard rate, induced by the anticipation of the future reduction in benefit payments (Mortensen, 1977; van den Berg, 1991), (ii) exogenous time dependence of the hazard rate induced e.g. by stigma (Vishvanath, 1989; Blanchard and Diamond, 1994), and (iii) influence of unobserved heterogeneity (Heckman and Singer, 1984; van den Berg and van Ours, 1994), that obtains through unobservability of the results of the means test. ${ }^{18}$ As one can see from the contributions (20a)-(20d) all these effects are readily identifiable. Our parameter

\footnotetext{
${ }^{17}$ We did experiment with a generalisation replacing 2 by some parameter to be estimated. This did not turn out to be viable, however.

${ }^{18}$ Of course one can also think of some additional sources of unobseved heterigeneity. In this case the model is extended in a standard way, with heterogeneity enetering additively (or multiplicatvely) into either $\eta_{1,2}$ or $\lambda$, after which a marginal contribution to the likelihood, with unobserved component integrated out, is considered. However, unlike with unobserved outcome of the means test, this would already be the heterogeneity induced by some unknown source, which makes its modelling less interesting. Moreover, and most importantly, the computational burden of fitting the model with an additional unobserved heterogeneity increases immensely.
} 
vector $\boldsymbol{\xi}$ is a set $\boldsymbol{\xi}=\left\{\lambda_{0}, \alpha, \sigma, \eta_{0}, \delta_{j}, \boldsymbol{\beta}, \boldsymbol{\gamma}\right\}_{j=1,2}$. The separation rate parameters $\lambda_{0}$ and $\boldsymbol{\gamma}$ are always identified by the data on the job duration $l$ and observed characteristics, as becomes obvious from (20d). Given $\lambda(\mathbf{x})$, scale parameters $\left\{\eta_{0}, \boldsymbol{\beta}\right\}$ and exogenous time dependence parameters $\left\{\delta_{j}\right\}_{j=1,2}$ are identified from the subsample of nonentitled individuals (20c) and post-entitlement incremental durations in (20b), since endogenous time dependence for these is time-invariant. Given that exogenous time dependence is pinned down, the parameters $\alpha$ and $\sigma$, that shape the endogenous time dependence induced by anticipation of benefit reduction, are identified by the variables $b_{1}, b_{2}, \bar{s} \in \mathbf{z}$ in (20a). Finally, the fraction $\pi$ of those who pass the means test is always identified via observability of the outcome of this test in a subsample of individuals that fail to leave unemployment before the entitlement period is over, and transit to a lower-benefit regime. This is seen from (20b).

\subsection{Estimation results}

- Preliminary discussion

Table 1 reports estimation results for the specifications that exclude (left panel) and include (right panel) observed individual characteristics. Numerical complexity of the model makes us restricting attention on only a minimal number observed characteristics, which are $\operatorname{sex}\left(=1\right.$ if male) and region (=1 if an individual comes from East Germany). ${ }^{19}$

\begin{tabular}{lccccrrrr}
\hline \hline & Coeff. & \multirow{2}{*}{ SE } & z-Stat. & p-Value & Coeff. & SE & z-Stat. & p-Value \\
\hline \hline$\lambda_{0}$ & -3.7413 & 0.0652 & -57.3787 & 0.0000 & -3.8758 & 0.1314 & -29.4883 & 0.0000 \\
Sex & & & & & -0.2124 & 0.1334 & -1.5924 & 0.1113 \\
Region & & & & & 0.5781 & 0.1243 & 4.6505 & 0.0000 \\
$\eta_{0}$ & -2.7097 & 0.1436 & -18.8662 & 0.0000 & -2.6768 & 0.1487 & -17.9984 & 0.0000 \\
Sex & & & & & 0.0485 & 0.1260 & 0.3848 & 0.7004 \\
Region & & & & & -0.0960 & 0.1350 & -0.7113 & 0.4769 \\
$\alpha$ & 0.3165 & 0.1759 & 1.7991 & 0.0360 & 0.2911 & 0.1443 & 2.0169 & 0.0219 \\
$\sigma$ & 0.9380 & 0.1303 & 7.1973 & 0.0000 & 0.9510 & 0.0961 & 9.8993 & 0.0000 \\
$\delta_{1}$ & 0.0018 & 0.0042 & 0.4138 & 0.6790 & 0.0015 & 0.0038 & 0.3930 & 0.6943 \\
$\delta_{2}$ & 2.4987 & 0.8824 & 2.8317 & 0.0046 & 2.5488 & 0.9385 & 2.7158 & 0.0066 \\
$\pi$ & 0.2071 & 0.0282 & 7.3474 & 0.0000 & 0.2077 & 0.0315 & 6.5965 & 0.0000 \\
\hline
\end{tabular}

$\log \mathcal{L}$

$-2282.17$

$-2268.97$

Table 1 Estimation results ${ }^{20}$

\footnotetext{
${ }^{19}$ One evaluation of the total likelihood takes over 5 minutes with Matlab 6.1 on a laptop with $1.6 \mathrm{GHz}$ CPU and 0.99GB RAM. The demonstrtion optimization of the specifications in the left and right panels of Table 1 requires 15 and 26 hours, respectively, to converge.

${ }^{20}$ Since $\alpha \in[0,1]$ and $\sigma \in[0, \infty)$, p-Values for the significance tests for these two parameters are reported for a one-sided alternative $H_{a}: \alpha, \sigma>0$. Observed heterogeneity is jointly significant: the LR test statistic is 26.4031 and the corresponding p-Value is 0.0000 .
} 
As for the estimation results alone, our main finding is the significance of $\alpha$. This means that changes in optimal effort in response to any unemployment benefit reform, be it the reform of $b_{1,2}$ or of $\bar{s}$, will have a significant impact on the exit rate out of unemployment. This finding in particular can contribute to the empirical dispute about the dependence between unemployment benefits and exit decision. Evidence in the literature are conflicting with earlier Hujer and Schneider (1989) and Arulampalam and Stewart (1995) finding minor no negligible dependence and later Carling et al. (2001) and Røed and Zhang (2003) stating the opposite. Despite we do not rule out that for certain types of heterogeneous agents the change in benefits may play no role, our result on the significance of $\alpha$ shows that in sufficiently aggregate terms there exists a positive significant relationship between the reemployment risk and any change in the level of unemployment benefit payments. Consequently, any change in the design of unemployment benefit mechanism will induce a significant response on the macro level.

The next important finding is the role of unobserved heterogeneity. From tab. 1 we can see that $\pi$ is always significant at $5 \%$ level, implying that the prospect of not passing the means test significantly increases search effort. Along with that, both panels show that the estimate of $\delta_{1}$ is never significantly different from zero. This means that, once unobserved components are accounted for, the individual state dependence need not be inconsistent with that of Mortensen (1977) and van den Berg (1990). Thus, we find that it is the unobserved heterogeneity rather than the exogenous individual downward state dependence that is responsible for the declining nonparametric hazard rates in fig. 1.

Finally, from tab. 1 it is also easy to see that introduction of observed heterogeneity does not significantly influence the parameters responsible for the shape of the structural hazard function (i.e., $\alpha, \sigma, \delta_{1}$ and $\delta_{2}$ ). Thus, if one is not interested in policy modelling on sub-population level, fitting the model without $\mathbf{x}$, and thereby substantially reducing the estimation time, could already be sufficient.

- Predicting labour productivity $A$ and vacancy cost $\gamma$

After having estimated all the parameters in $\boldsymbol{\xi}$ we are left with determining $A$ and $\gamma$. The wage $w$ and tightness $\theta$ were taken as exogenous in this first part of the estimation which was built on the household side of the model only. As the wage and tightness are endogenous in general equilibrium, we now take the estimated parameters $\boldsymbol{\xi}$ and compute parameters $A$ and $\gamma$ using the full general equilibrium structure of our economy in the steady state (see sect. 3.3). We compute $A$ and $\gamma$ such that the average wage and average tightness in our sample result as general equilibrium endogenous variables in our model.

\section{$5 \quad$ Evaluating the labour market reforms}

In this chapter we use the structurally estimated parameters in order to describe the steady state equilibrium of 2004 and to evaluate the reforms effective as of January 2005. 


\subsection{The pre-reform steady state}

All parameters plus some selected endogenous variables are provided in tab. 2. As in the estimation procedure, the rate of time preference $\rho$ is chosen to match the annual interest rate of 3.7 percent. The bargaining power $\beta$ is set equal to .5. Using the results in in Table 1 and the observable characteristics we can predict the values of the separation rate $\lambda=\Sigma_{i} \exp \left(\mathbf{x}_{i}^{\prime} \gamma\right)$ and the spell-effect parameter $\eta_{0}=\Sigma_{i} \exp \left(\mathbf{x}_{i}^{\prime} \boldsymbol{\beta}\right)$ from the unconditional model (differing from the conditional model by around 1\%o). The other estimated and predicted parameters are directly taken from the previous section. Labour productivity of $A$ is just above the endogenous wage rate of 2155 DM (German marks), leaving the difference for firms to pay for vacancy costs $\gamma$.

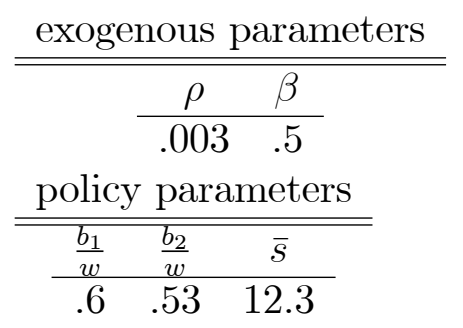

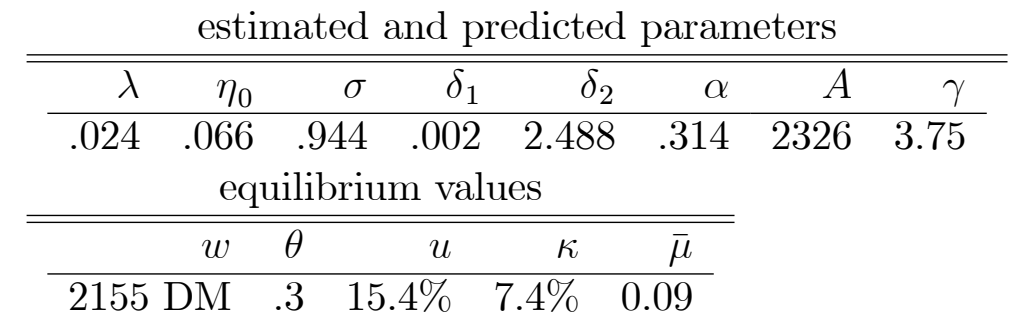

Table 2 Parameter and selected equilibrium values (see text above for details)

In the pre-reform steady state, benefit payments of both short-term and long-term unemployed workers depend on the previous wage. The replacement rates are given by $b_{i} / w$ and are sample means for those entitled to UI and UA payments. These ratios are pretty close to statutory replacement rates. We do need to take unobserved heterogeneity as "discovered" in the estimation into account, however. As only an estimated share of $\pi=20.7 \%$ pass the means test (see tab. 1), unemployment insurance payments of our representative agent are the product of the replacement rate, the previous wage and the share $\pi, b_{2}=.53 w * \pi$.

Average sample entitlement to UI payments is 12.3 months, again for those entitled to UI payments. Comparing our tax rate $\kappa$ and unemployment rate $u$ to actual social security contribution rate (this is the only purpose of taxes in our model) of 0.06 and the actual unemployment rate of $15.4 \%$, our model fits real data relatively well.

For comparative statics below, we will take the exogenous parameters, the estimated and the predicted parameters as given. We will then change policy parameters to understand the effects on equilibrium values.

Although the economy is in the steady state, there are still dynamics on the micro level. At any point in time individuals find and lose jobs. Figure 2 illustrates the developments on the micro level. The upper left panel shows that and how the estimated exogenous spell-effect falls over time. The value of being unemployed thereby unambiguously falls over time. This is shown by the upper right panel and needs to hold generally as (A.2) in the appendix shows. The intuition is simple: If there was no spell-effect $(\eta(s)$ is constant), a long-term unemployed would live in a stationary world and the value of being a long-term unemployed would be stationary as well. With a negative spell-effect, the job finding rate - 
taking optimally chosen effort into account - goes down and the value of being unemployed approaches a lower limit determined by the lower limit of $\eta(s)$.
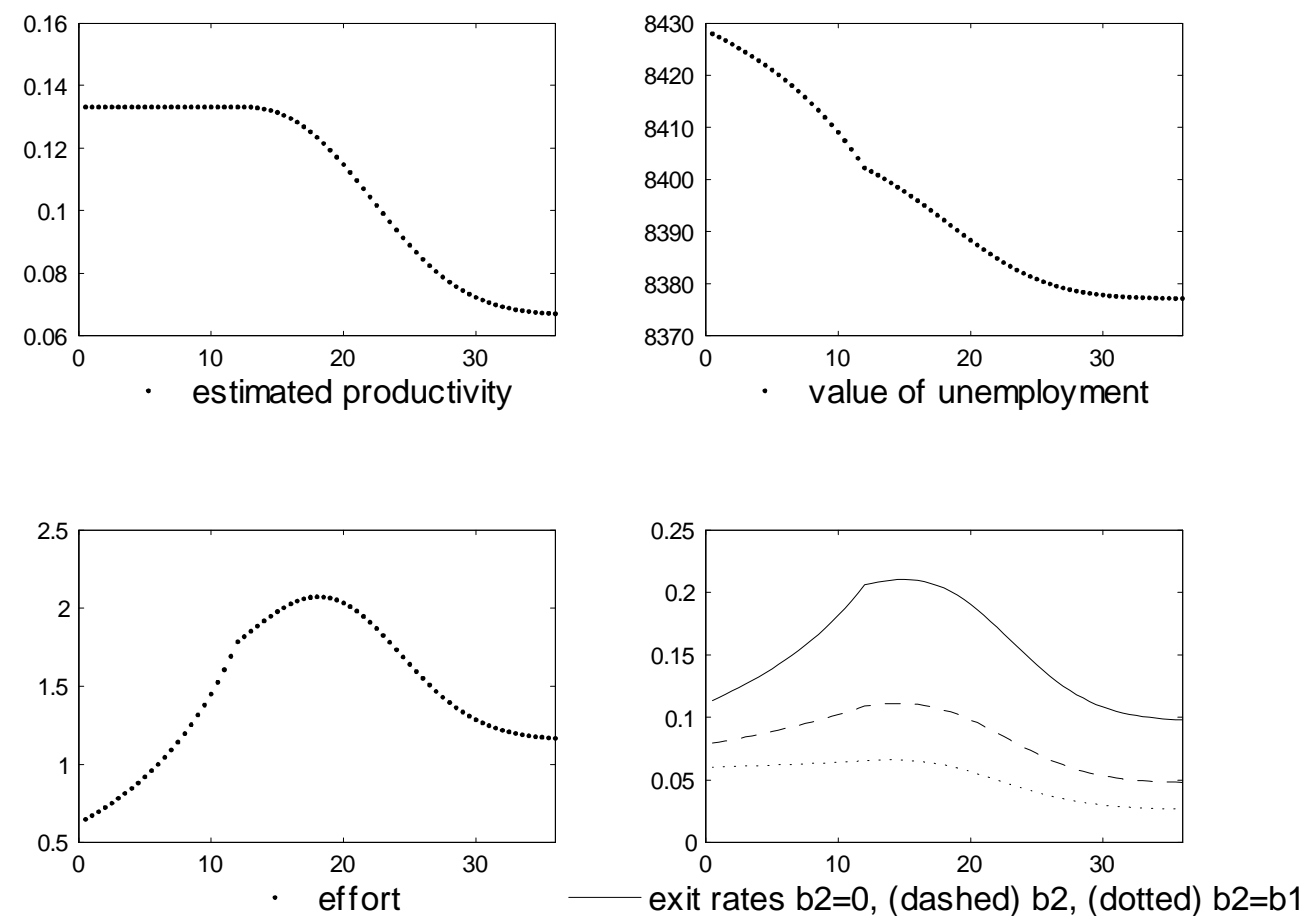

Figure 2 Productivity, effort, the exit rate and the value of being unemployed as a function of the spell s (in months)

The optimal reaction of the unemployed worker is shown by the lower left panel. Effort unambiguously increases during the entitlement period of length $\bar{s}=12.3$ months. Given that the estimated spell-effect is basically constant until around $s=15$, this reflects the rising incentives to search hard, the closer $\bar{s}$ is. Once an individual is long-term unemployed and the negative spell-effect sets in, optimal effort is the outcome of the interplay of the spell effect (lower $\eta(s)$ reduces optimal effort) and the potential gain from finding a job. This can be seen from the first-order condition in (6) or, more directly, from (A.1) in the appendix. As gains increase due to a falling value of being unemployed, this second effect tends to increase effort. With our estimates, effort further increases when the individual becomes a long-term unemployed as the falling value of being unemployed causes higher effort. After some time, however, the increase in the gain of finding a job is no longer strong enough to compensate the "discouraging" effect from the spell-effect. Search effort eventually falls and approaches a constant. The fact that unemployed workers finally "give up" is ultimately the effect of the exogenous negative spell-effect.

Effort expressed in consumption is equivalent to consumption loss ranging from 12 to 21 percent. $^{21}$ The exit rate shows paths for $b_{2}=0$, average $b_{2}$ and $b_{2}=b 1$. Average $b_{2}$ is the one in our pre-reform steady state, we will return to the other ones in our analysis of the reform.

\footnotetext{
${ }^{21}$ Share of consumption $x$ lost due to search is determined by $([1-x] b(s))^{1-\sigma} /(1-\sigma)=$ $b(s)^{1-\sigma} /(1-\sigma)-\phi(s)$.
} 


\subsection{The effects of the reforms}

Labour market reforms were characterized by a reduction in UA benefits $b_{2}$ and entitlement length $\bar{s}$. Benefits decreased on average by $7 \%$, average entitlement length $\bar{s}$ dropped from 12.3 to 10.8 , i.e. by $12.2 \%$. We first analyse each change individually before we combine the changes and also allow for economic growth.

- A decrease of unemployment assistance benefits $b_{2}$

Figure 3 shows the effects of a decreasing $b_{2}$ on the labour market (when reading horizontal axes from right to left). As effort of unemployed workers increases, it becomes more likely that a job will be found faster. Consequently, the long-term unemployment and also the overall unemployment rate in the economy go down. Not surprisingly, less unemployment implies a higher vacancy-unemployment ratio $\theta$, which means that the labour market becomes tighter for firms. This also leads to higher net wages, which becomes clear from the wage equation (11) once the positive tightness effect dominates the negative effort effect. Finally, the tax rate goes down, because reduction in $b_{2}$, and therefore in equilibrium unemployment, implies less benefits to finance (and this also by a higher number of employed workers). So without considering any welfare questions, the cut of $b_{2}$ by the Hartz IV reforms seems to be a good move against the too generous institution.
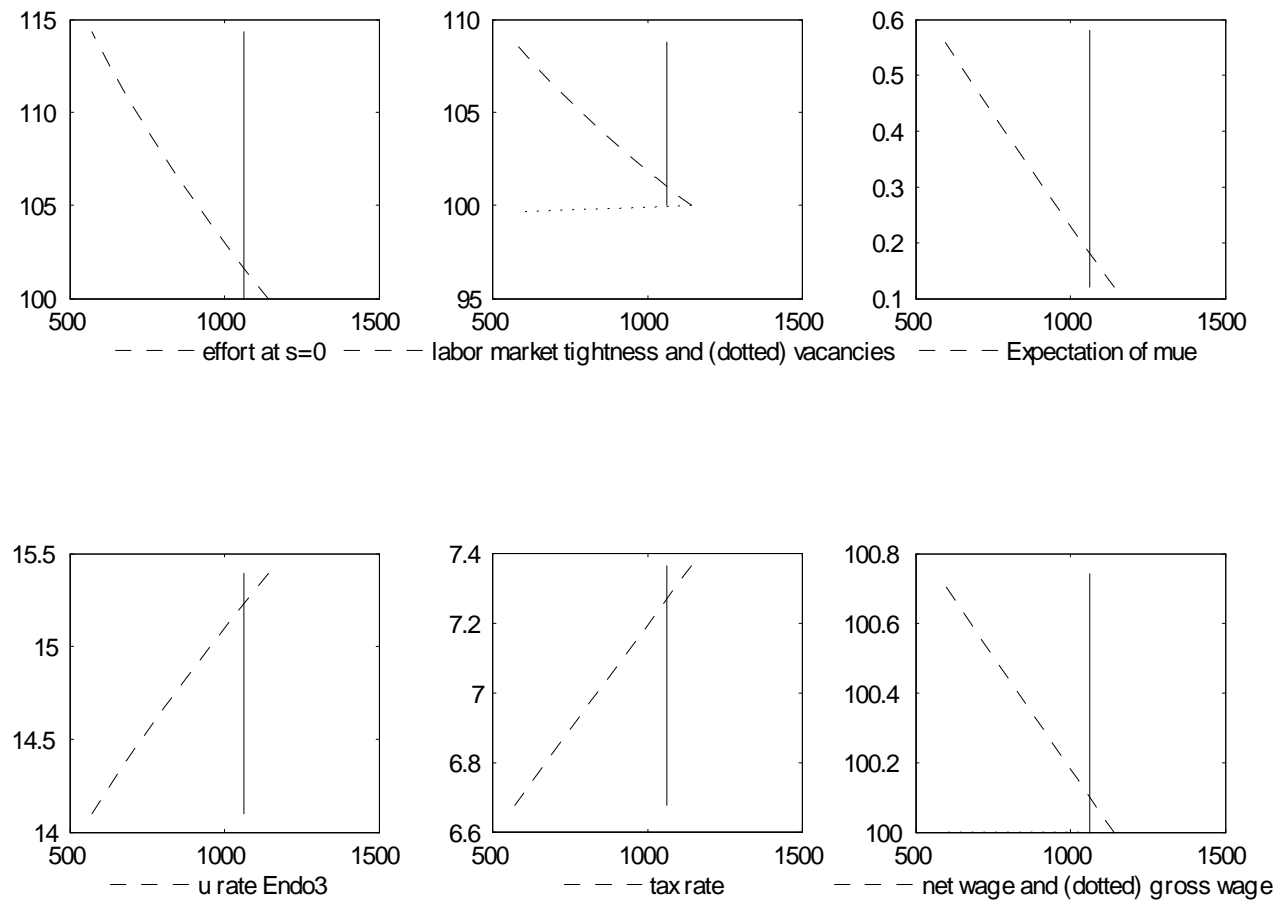

Figure 3 (Un)employment effects of a drop in long-term benefits $b_{2}$

When we add welfare measures in fig. 4, however, the unambiguously positive impression of the reform disappears. It makes perfect sense that both short-term and long-term unemployed are worse off in terms of their expected lifetime values. The long-term unemployed 
are directly hurt by the cut in $b_{2}$ and the short-term unemployed are now subject to higher search pressure, because in the nearest future their benefits may drop from $b_{1}$ to already lower level of $b_{2}$. The value of unemployment depends negatively on search effort and positively on exit rate, which can be seen from equations (5) and (17). So, as fig. 4 suggests, in both groups, the effort effect has obviously outweighed the employment effect. But it is even more remarkable that also firms and employed workers become worse off. The loss of the employed workers is slight and reflects the fact that net wage, even though increases, is not high enough to compensate for the prospective loss once becoming unemployed in the future (see 4). Firms lose because the increase in net wage turns out to be higher than the decrease in the tax rate, so gross wage goes up, implying lower equilibrium profit. All in all, these results evidently explain why the total steady state welfare of the economy is expected to decrease due to Hartz IV reform. This result is very interesting because it seems generally accepted that a weakening such institutions as "benefits" is economically and socially desirable in a welfare state.
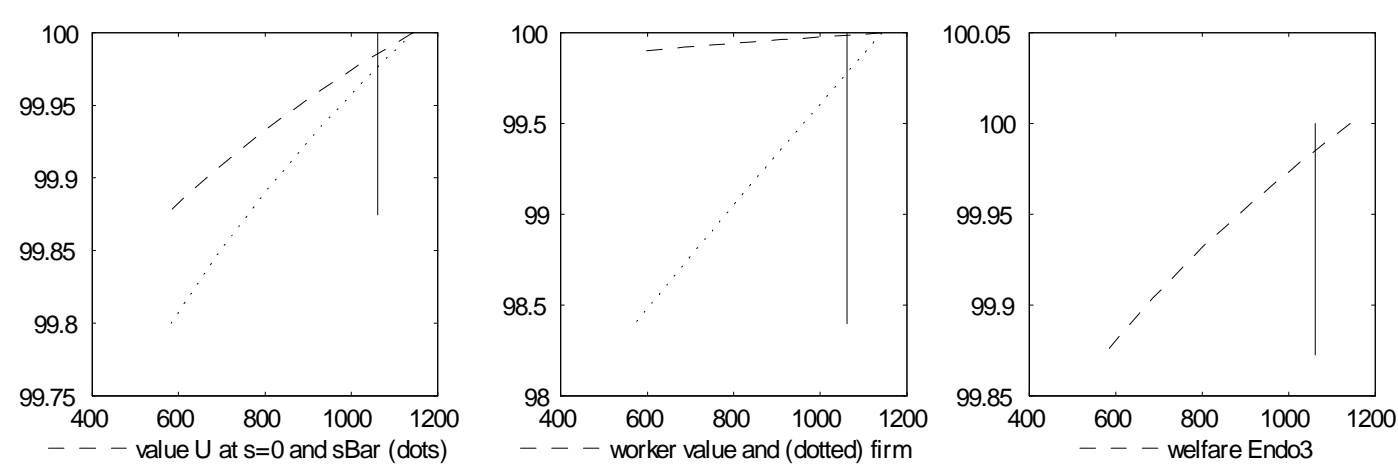

Figure 4 Welfare effects of decreasing $b_{2}$

Quantitatively, the effects on welfare seem to be very small - the reduction is less than $.1 \%$. This is not surprising, however, as we look at intertemporal utility. With $15 \%$ being unemployed in our framework and $1 / 3$ become long term unemployed only, only $5 \%$ of the population is affected by the reform. In an intertemporal sense, income is reduced only during $5 \%$ of ones' lifetime. When current income of these $5 \%$ is reduced by $7 \%$, lifetime income is reduced by $.35 \%$. Hence, the apparently low quantitative effects make sense.

- Changing the entitlement period $\bar{s}$ and economic growth

A reduction in the length of entitlement of unemployment insurance payments has qualitatively almost identical effects to a reduction of $b_{2}$. The only difference consists in the gross wage and the value of a firm. As the gross wage now decreases as $\bar{s}$ falls, the firm value $J$ increases. Even though the increase of $J$ is by more than $10 \%$, overall welfare still falls by the same order of magnitudes as in the $b_{2}$ reduction case. (See the companion policy paper by Launov et al., 2009, for a more explicit discussion.)

Not surprisingly, when a joint analysis of level and length of benefit payments is undertaken, unemployment reduction is stronger as the value of being unemployed drops more 
heavily. Quantitatively, no drop is stronger than 1\%, however. Overall welfare effects remain in the range as seen for $b_{2}$.

A final important question to be asked is how much of the efficiency gains remain if economic growth is taken into account. Real GDP in Germany grew by 0.8 percent in 2005 and by 2.9 percent in 2006 . When this growth effect is captured here by letting $A$ increase by this amount when evaluating the effects of the reform, the unemployment reduction is stronger. From January 2005 to January 2007 unemployment in Germany fell from $12.3 \%$ to $10.2 \%$. Subtracting the pure growth effect (obtained from letting only $A$ change) shows that the reduction in unemployment explained by the reform is still around one percentage point only.

\subsection{Understanding the effects of the reform}

- An analytical benchmark

We can summarize the above analysis by saying that the labour market reform reduced the unemployment rate by one percentage point and led to an overall drop of welfare of half a percentage point. To gain intuition why welfare fell, let us recall the classic result from optimal fair insurance. An individual can be in two states $w$ and $b$ and expected utility is given by $p u(w)+(1-p) u(b)$. The government finances benefits by a labour tax and equates income with expenditure, $\kappa w /(1-\kappa) p=b(1-p)$, where $p$ is both the probability of being employed and the share of the population which is employed. Maximizing expected utility given this constraint requires an equalization of marginal utilities in both states, $u^{\prime}(w)=u^{\prime}(b)$ and a tax that implies $w=b$. Identity of benefits to net wage provides perfect insurance and consumption smoothing in the absence of incentive effects.

Let us now replicate this result for our setup. Assume that the path of effort is not affected by the reform. Assume further that the gross wage and the number of vacancies are not affected. Then, a change in $b_{2}$ is simply a transfer of income from the state of being employed to the state of being long-term unemployed through the fiscal system, i.e. through the tax on labour income. When we maximize the social welfare function (12) by choosing $b$ and letting the tax adjust accordingly, we obtain (see app. B.10)

$$
V^{\prime}(w) \frac{U_{\text {long }}}{N}=\frac{N-L}{N} \int_{\bar{s}}^{\infty} \frac{d}{d b_{2}} V\left(b_{2}, s\right) f(s) d s .
$$

In the light of standard results of optimal insurance, this expression is easy to understand. Our optimality also compares marginal utilities (i.e. intertemporal utilities, the value functions) but it also takes the distribution of the unemployment spell into account. This occurs in two ways: First, through the share of long-term unemployed in the total number of unemployed and second, through the density $f(s)$ - how often and how long this state of being long-term unemployed occurs. The first effect is due to the fact that this maximization problem takes the third state - short-term unemployed - as given. If there were no short-term unemployed, i.e. if $\frac{U_{\text {long }}}{N}=\frac{N-L}{N}$, the optimality condition would read $V^{\prime}(w)=\int_{\bar{s}}^{\infty} \frac{d}{d b_{2}} V\left(b_{2}, s\right) f(s) d s$. This is the optimality condition from a static insurance model extended for the distribution as captured by $f(s)$. 
- Quantitative benchmark results

When we want to understand how high $b_{2}$ resulting from (22) is, we simply need to solve our model for an exogenous gross wage, exogenous number of vacancies, an endogenous tax $\kappa$ but exogenous effort. Looking at unemployment effects is meaningless as we assumed that effort is identical to the pre-reform steady state, i.e. given by the path as visible in fig. 2. The following figure therefore shows us the pure insurance effect of $b_{2}$, i.e. the effect of changes in $b_{2}$ on the tax rate, the net wage, the value of having a job and being short- and long-term unemployed and overall welfare.

- work in progress -

Figure 5 The insurance effect of unemployment benefits $b_{2}$

- Insurance and incentive effects of the reform

We now allow for incentive effects as well in order to see by how much the optimal $b_{2}$ in fig. 5 reduces if effort effects are taken into account. We now solve our model as in the previous figure, i.e. an exogenous gross wage, exogenous number of vacancies, an endogenous tax $\kappa$, only that effort now reacts to changes in $b_{2}$. Results are in the following figure.

- work in progress -

Figure 6 The insurance and incentive effect of unemployment benefits $b_{2}$

When we look at these results, the complete general equilibrium effects in fig. 3 and 4 follow next. t.b.c.

\section{Conclusion}

We have developed an estimable search and matching model with endogenous effort under time-dependent unemployment benefits. The main extension compared to the existing search and matching literature is the endogenous distribution of unemployment duration that arises due to individual choice of search intensity in a nonstationary environment. A link between these micro-dynamics and macro quantities like the unemployment rate was developed using tools from the literature on Semi-Markov processes.

The theoretical model provides the density of unemployment duration of an individual being a function of various model parameters. This density provides the basis for structural estimation via maximum likelihood. General equilibrium policy analyses were performed using the parameter estimates of the best fitting specification.

Simulations enable us to assess individual and aggregate labour market and welfare effects of changes in the length and level of unemployment benefit payments. As an example of such a reform, we evaluate the German Hartz IV reform of 2005. Total unemployment decreases due to the reform and so do government transfers to the unemployed. At the same time, despite unemployment and social security contributions do go down, the welfare changes 
for the economy as a whole are negative. While it is seems obvious (given the design of the reform) that the unemployed, especially the long-term unemployed, lose, workers and even firms lose. So when it comes to a normative evaluation, the advantages of shortened institutions are no longer unambiguous, given that efficiency effects have to be weighed against insurance effects.

\section{A Appendix}

\section{A.1 Data}

The data comes from the German Socio-Economic Panel (SOEP). The SOEP is a panel surveying households on an annual basis. The survey is coordinated by the Deutsche Institut für Wirtschaftsforschung (Berlin, see www.gsoep.de).

We draw a flow sample of entrants to employment and unemployment at each month of years 1997-98. The choice of the year of sampling is determined by the fact that no changes to either benefit level or entitlement length were made between the 1st of January 1997 and the 1st of January 2005, when Hartz IV reform came into power. With December 2003 being the latest month of our observation period we end up with a sample that describes a stationary entitlement-benefit environment and provides a fairly reliable information on long-term unemployment (only $8.36 \%$ of unemployment durations in our sample are rightcensored). For each entrant we retrieve the duration of stay in the current state since the moment of entry. Following van den Berg and Ridder (1998), p.1194, we refrain from considering individuals that allow transitions to the states other than full-time employment or unemployment within the above defined 01.97-12.98 window.

Units of measurement are months for the duration data and German Marks for the wage data. Wage is the average monthly wage for the months employed within a year prior to job loss; prices are those of 1997. Descriptive statistics can be found in tab. 3 .

\begin{tabular}{lrrlrc}
\hline \hline Unemployment: & Mean & Std. Dev. & & Mean & Std. Dev. \\
\hline Duration $(s)$ & 8.12 & 11.67 & Share of entitled & 0.5791 & 0.4944 \\
UI benefits $\left(b_{1}\right)$ & 1316.98 & 505.76 & Share of $\bar{s}=12$ among entitled & 0.4948 & 0.5013 \\
Entitlement $(\bar{s})$ & 12.30 & 5.58 & Observed share passing the test & 0.5263 & 0.5130 \\
Wage $(w)$ & 2154.94 & 921.87 & & & \\
\# obs., total & 335 & & \# obs., censored & \\
& & & & \\
\hline \hline Employment: & Mean & Std. Dev. & & \\
\hline Duration $(l)$, cens. & 53.12 & 27.63 & & & \\
Duration $(l)$, all & 27.37 & 27.38 & & & \\
\# obs., total & 408 & & \# obs., censored & & \\
\hline
\end{tabular}

Table 3 Descriptive statistics 
It is important to notice that GSOEP data do not contain information on the length of entitlement to UI benefits. There exist, however, strict and relatively simple rules that allow computing the length of entitlement once we know the length of previous job durations and the age of an individual. For this reason, for every person that enters unemployment we also have to retrieve his/her previous job history. In addition to that, previous job history provides us with the record of the latest wage earned.

Mean of the vacancy-unemployment ratio from 1997 to 2004 in Germany is $\theta=0.3{ }^{22}$

\section{A.2 Steady state solution}

We solve for the steady state of the model by separating the model into two "blocks".

- Block 1: Household behaviour

Given the functional forms for utility and the spell-effect in (17) and (18), the first-order condition for effort (6) reads

$$
\phi(s)=\left\{\alpha \eta(s) \theta^{\alpha}[V(w)-V(b(s), s)]\right\}^{\frac{1}{1-\alpha}} .
$$

It holds for both short- and long-term unemployed. Plugging this into the Bellman equation for the unemployed (5) and expressing it as a differential equation in $s$ gives

$$
\dot{V}(b(s), s)=\rho V(b(s), s)-\frac{b(s)^{1-\sigma}}{1-\sigma}+\frac{\alpha-1}{\alpha}\left[\alpha \eta(s) \theta^{\alpha}\right]^{\frac{1}{1-\alpha}}[V(w)-V(b(s), s)]^{\frac{1}{1-\alpha}},
$$

which is again valid for both short- and long-term unemployed. As the value of being unemployed an instant before and an instant after becoming a long-term unemployed is identical, we impose $V\left(b_{1}, \bar{s}\right)=V\left(b_{2}, \bar{s}\right)$ when solving this differential equation. Finally, since for an infinite unemployment spell, the spell-effect in (18) becomes a constant, $\lim _{s \rightarrow \infty} \eta(s)=\eta_{2}$ and all other quantities are stationary as well, we get the terminal condition for (A.2) by using $\lim _{s \rightarrow \infty} \dot{V}\left(b_{2}, s\right)=0$,

$$
\rho V\left(b_{2}\right)=\frac{b_{2}^{1-\sigma}}{1-\sigma}-\frac{\alpha-1}{\alpha}\left[\alpha \eta_{2} \theta^{\alpha}\right]^{\frac{1}{1-\alpha}}\left[V(w)-V\left(b_{2}\right)\right]^{\frac{1}{1-\alpha}} .
$$

The Bellman equation for the employed worker (4) can be written with the explicit utility function as

$$
V(w)=\frac{1}{\rho+\lambda}\left(\frac{w^{1-\sigma}}{1-\sigma}-\psi+\lambda V\left(b_{1}, 0\right)\right) .
$$

Now imagine we insert $V(w)$ from (A.4) into (A.2) and (A.3). Imagine further that we know all parameters and assume, for the time being, some values for $w$ and $\theta$. Then we can solve the differential equation (A.2) starting from some initial value $V\left(b_{1}, 0\right)$ and see whether the solution for $s \rightarrow \infty$ is identical to $V\left(b_{2}\right)$ from (A.3). If it does not, we need to adjust our initial guess $V\left(b_{1}, 0\right)$ until it does. Hence, with some exogenous $w$ and $\theta$, we have obtained the time path of effort over the unemployment spell, $\phi(b(s), s)$, the spell-path of the value of being unemployed, $V(b(s), s)$, and the value of a job $V(w)$.

\footnotetext{
${ }^{22} w=2250$ Deutsche Mark is the average monthly net wage before the worker became unemployed, with job being lost during 1997.
} 
- Block 2: Wage, tightness and vacancy filling rate

Given the equilibrium values $\{\phi(b(s), s), V(b(s), s), V(w)\}$ as a function of $w$ and $\theta$, we now endogenize $w$ and $\theta$.

The Bellman equation for the firm and the free entry result, (8) and (10), gives us

$$
\frac{A-\frac{w}{1-\kappa}}{\rho+\lambda}=\gamma \frac{\theta}{\bar{\mu}} \text {. }
$$

The bargaining equation (11) reads with an explicit utility function (17)

$$
\frac{w^{1-\sigma}}{1-\sigma}-\psi+\frac{\beta}{1-\beta} \frac{w}{1-\kappa}=\left[\frac{b_{1}^{1-\sigma}}{1-\sigma}-\phi(0)\right]+\frac{\beta}{1-\beta}[A+\theta \gamma],
$$

where $\phi(0)$ is the optimal search effort at the instant of entry into unemployment, which is given from (A.1). The above two equations require the average exit rate $\bar{\mu}$ and the tax rate $\kappa$.

The average rate $\bar{\mu}$ is given by (9) which can easily be computed given that, after having solved block 1 , the exit rates $\mu($.$) are known from (18) and the density f(s)$ can therefore be computed from (2). ${ }^{23}$ The tax rate $\kappa$ makes the government budget constraint (3) hold and is given by

$$
\kappa=\frac{\frac{b_{1} U_{\text {short }}+b_{2} U_{\text {long }}}{w L}}{1+\frac{b_{1} U_{\text {short }}+b_{2} U_{\text {long }}}{w L}} .
$$

Given the density $f(s)$, one can compute the number of short-term and long-term unemployed on the right-hand side of this expression from $U_{\text {short }}=U \int_{0}^{\bar{s}} f(s) d s$ and $U_{\text {long }}=$ $U-U_{\text {short }}$ where $U$ is the total number of unemployed. The number of unemployed in turn follows from (16), using (13a,b) and (14) which we can now solve, given again that exit rates are known from block 1.

Hence, we are basically left with (A.5) and (A.6) to determine the missing endogenous variables $w$ and $\theta$. After having solved block 1 with a guess of $w$ and $\theta$, we verify whether this guess fulfills (A.5) and (A.6). If not, we (matlab) adjusts the guess until we find a solution.

Appendix ?? describes the numerical implementation in matlab. Appendix B.5 describes the numerical implementation for the estimation procedure.

\section{A.3 A Semi-Markov process}

This is a very short version of a more explicit analysis of Semi-Markov processes and their potential applications (see Schumm, 2009). The first subsection describes the general approach to Semi-Markov processes while the second adapts it to our question.

\footnotetext{
${ }^{23}$ Given the regime change at $\bar{s}$, the density in (2) will have a hurdle structure. Denoting the exit rate $\mu($.$) by \mu_{1}(s)$ for short-term unemployed and $\mu_{2}(s)$ for long-term unemployed, we get

$$
f(s)=\left\{\begin{array}{ll}
\mu_{1}(s) e^{-\int_{0}^{s} \mu_{1}(u) d u} & \text { for } s \leq \bar{s} \\
\frac{\exp \left\{-\int_{0}^{\bar{s}} \mu_{1}(u) d u\right\}}{\exp \left\{-\int_{0}^{\bar{s}} \mu_{2}(u) d u\right\}} \mu_{2}(u) e^{-\int_{0}^{s} \mu_{2}(u) d u} & \text { for } s>\bar{s}
\end{array} .\right.
$$

The expression for $s>\bar{s}$ is the probability of surviving $\bar{s}$ with a high level of benefit payments times the density of unemployment duration conditional on the expiration of entitlement, i.e. on $s>\bar{s}$, and transition to a lower level of benefit payments.
} 


\section{A.3.1 The general approach}

This follows Kulkarni (1995) and Corradi et al. (2004). The original work is by Pyke $(1961 \mathrm{a}, \mathrm{b}) .{ }^{24}$ Let $Y_{n}$ denote the state of a system after the $n$th transition. Let this state be $i$. Let the point in time of the $n$th transition be denoted by $S_{n}$. Define the probability that the system after the next transition is in $j$ and that this transition takes place within a period of length $x$ or shorter, conditional on the system being in $i$ after the $n$th transition, as

$$
Q_{i j}(x) \equiv P\left\{Y_{n+1}=j, S_{n+1}-S_{n} \leq x \mid Y_{n}=i\right\} .
$$

The probability that any transition takes place is then given by summing up the probabilities for each $j, Q_{i}(x)=\Sigma_{j \neq i} Q_{i j}(x)$, not taking into account transitions from $i$ to $i{ }^{25}$ The probability that the system will be in $j$ in $\tau$ is given by

$$
p_{i j}(\tau)=\left(1-Q_{i}(\tau)\right) \delta_{i j}+\Sigma_{k \neq i} \int_{0}^{t} p_{k j}(\tau-x) d Q_{i k}(x) .
$$

The interpretation of this integral equation is as follows: the first part of the right hand side gives the probability that the system, being currently in state $i$, never leaves state $i$ until $\tau$. In this case $j=i$ and $\delta_{i j}=1$, so $1-Q_{i}(\tau)$ is the survival probability in state $i$. If $j \neq i$, $\delta_{i j}=0$. The second part of the right hand side collects all cases in which the transition from $i$ to $j$ (which includes $i$ ) occurred via another state $k \neq i$. First, we take the probability that the process stayed in state $i$ for a period of length $x$ and passed to state $k$ then (captured by $\left.Q_{i k}(x)\right)$. Then we need the probability that the process which is in state $k$ after $x$ will be in state $j$ at $\tau$ (captured by $p_{k j}(\tau-x)$ ). As the transition from $i$ to $k$ can be anywhere between 0 and $\tau$, we have to integrate over $x$ in order to cover all possible transitions.

Equation (A.8) can slightly be rewritten, provided that $Q_{i k}(x)$ is once differentiable (which holds for our case), as

$$
p_{i j}(\tau)=\left(1-Q_{i}(\tau)\right) \delta_{i j}+\Sigma_{k \neq i} \int_{0}^{t} p_{k j}(\tau-x) \frac{d Q_{i k}(x)}{d x} d x .
$$

The derivative $d Q_{i k}(x) / d x$ now gives the density of going from $i$ to $k$ after duration $x$. Multiplied by the probability of subsequently going from $k$ to $j$ gives the density of ending up in $j$ after having gone to $k$ after $x$. Integrating over all durations $x$ gives the probability of starting in $i$ and being in $j$ at $\tau$.

\section{A.3.2 Our two-state system}

We now need to adjust the notation such that it suits our purposes. We look at a worker who just moved in $t$ (like today) into either employment $e$ or unemployment $u$. Define $Q_{e u}(\tau)$

\footnotetext{
${ }^{24}$ We are grateful to Ludwig Fahrmeir for comments on Semi-Markov processes. For an excellent introduction in German, see Fahrmeir et al. (1981).

${ }^{25}$ We differ from the notation in the cited literature in that we explicitly write $j \neq i$ here or $k \neq i$ below. This is equivalent to setting the transition rate from $i$ to $i$ to zero. As our application does not have transitions from $i$ to $i$ (i.e. transition rates from $i$ to $i$ are zero), we find using $j \neq i$ explicitly more intuitive for our purpose.
} 
as the probability that a worker who just found a job in $t$ "jumps" to $u$ in a period of time shorter or equal to $\tau-t$. With a duration $s$ dependent arrival rate $\lambda(s(v))$, this is then simply given by

$$
Q_{e u}\left(\tau \mid t_{e}\right)=1-e^{-\int_{t}^{\tau} \lambda(s(v)) d v}
$$

where $s(v)=v-t$ is the duration in her current state. In perfect analogy and using a spelldependent arrival rate $\mu(s(v))$, we get $Q_{u e}(\tau)=1-e^{-\int_{t}^{\tau} \mu(s(v)) d v}$. For the complementary events - remaining in a given state - the probabilities are simply $Q_{e e}(\tau)=1-Q_{e u}(\tau)$ and $Q_{u u}(\tau)=1-Q_{u e}(\tau)$. The probabilities that a transition takes place at all in this two state process are

$$
Q_{e}(\tau) \equiv Q_{e u}(\tau), Q_{u}(\tau) \equiv Q_{u e}(\tau) .
$$

With two possible states, we have four transition probabilities for the future: an unemployed (employed) person can either be unemployed or employed at some future point in time $\tau$. Two are redundant as the probability of e.g. an unemployed worker of being employed is complementary to the probability of being unemployed, $p_{u e}(\tau)=1-p_{u u}(\tau)$, and similarly $p_{e e}(\tau)=1-p_{e u}(\tau)$. Hence, we only focus on $p_{u u}(\tau)$ and $p_{e u}(\tau)$. These probabilities are, using the general equation (A.9),

$$
\begin{aligned}
& p_{u u}(\tau)=1-Q_{u}(\tau)+\int_{t}^{\tau} p_{e u}(\tau-v) \frac{d Q_{u e}(v)}{d v} d v, \\
& p_{\text {eu }}(\tau)=\int_{t}^{\tau} p_{u u}\left(\tau-v \mid t_{u}\right) \frac{d Q_{e u}(v)}{d v} d v .
\end{aligned}
$$

These equations can be most easily be understood by looking at the following figure.

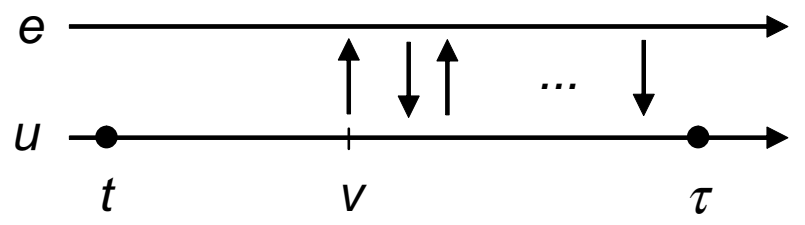

Figure 7 Illustrating transition probabilities

Let's consider $p_{u u}(\tau)$ : An individual unemployed in $t$ can be unemployed in $\tau$ by always remaining unemployed. This is the term $1-Q_{u}(\tau)$. The individual can be unemployed in $\tau$ by remaining unemployed until $v$ where she jumps into employment, the density for which is $d Q_{u e}\left(v \mid t_{u}\right) / d v$. After $v$, the probability of returning to unemployment in the remaining time span of $\tau-v$ is $p_{e u}(\tau-v)$. Note that this probability includes an arbitrary number of transitions larger than zero in this remaining period $\tau-v$. In contrast to integrating over $x$ as in (A.9), we integrate over the point in time $v$ here simply as this is the more intuitive way.

As a last step, we need to determine the two derivatives $d Q_{u e}(v) / d v$ and $d Q_{e u}(v) / d v$. Given duration-dependent arrival rates, the derivatives of (A.10) are,

$$
\begin{aligned}
& \frac{d Q_{u e}(v)}{d v}=e^{-\int_{t}^{v} \mu(s(y)) d y} \frac{d}{d v} \int_{t}^{v} \mu(s(y)) d y=e^{-\int_{t}^{v} \mu(s(y)) d y} \mu(s(v)) \\
& \frac{d Q_{e u}(v)}{d v}=e^{-\int_{t}^{v} \lambda(s(y)) d y} \frac{d}{d v} \int_{t}^{v} \lambda(s(y)) d y=e^{-\int_{t}^{v} \lambda(s(y)) d y} \lambda(s(v)) .
\end{aligned}
$$


Given (A.11) and the derivatives, the equations (A.12) become

$$
\begin{aligned}
& p_{\text {uu }}(\tau)=e^{-\int_{t}^{\tau} \mu(s(y)) d y}+\int_{t}^{\tau} p_{\text {eu }}(\tau-v) e^{-\int_{t}^{v} \mu(s(y)) d y} \mu(s(v)) d v, \\
& p_{\text {eu }}(\tau)=\int_{t}^{\tau} p_{\text {uu }}(\tau-v) e^{-\int_{t}^{v} \lambda(s(y)) d y} \lambda(s(v)) d v .
\end{aligned}
$$

The final adjustment we need to make is to replace $\lambda(s(v))$ by $\lambda$ as the separation rate is assumed to be constant. This then gives equations (13) in the main text.

\section{B Appendix}

All references to appendices starting with $B$ are available upon request.

\section{References}

Abbring, J., G. van den Berg, and J. van Ours (2005): "Effect of Unemployment Insurance Sanctions on the Transition rate from Unemployment to Employment," Economic Journal, $115,602-630$.

Acemoglu, D., and R. Shimer (1999): "Efficient Unemployment Insurance," Journal of Political Economy, 107, 893-928.

Albrecht, J., and S. Vroman (2005): "Equilibrium Search with Time-varying Unemployment Benefits," The Economic Journal, 115, 631-648.

Arulampalam, W., and M. Stewart (1995): "The Determinants of Individual Unemployment Duration in an Era of High Unemployment," Economic Journal, 105, 321-332.

Blanchard, O., and P. Diamond (1994): "Ranking, Unemployment Duration, and Wages," Review of Economic Studies, 61, 417-434.

Blanchard, O., and J. Wolfers (2000): "The Role of Shocks And Institutions In the Rise Of European Unemployment: The Aggregate Evidence," Economic Journal, 110, C1-C33.

Blos, K., and H. Rudolph (2005): "Verlierer, aber auch Gewinner," IAB Kurzbericht, 17, $1-6$.

Bontemps, C., J.-M. Robin, and G. van den Berg (1999): "An Empirical Equilibrium Job Search Model with Search on the Job and Heterogeneous Workers and Firms," International Economic Review, 40, 1039-1072.

Brügemann, B., and G. Moscarini (2007): "Rent Rigidity, Asymmetric Information, and Volatility Bounds in Labor Market," mimeo, Yale University.

Cahuc, P., and E. Lehmann (2000): "Should unemployment benefits decrease with the unemployment spell?," Journal of Public Economics, 77, 135-153. 
Cahuc, P., F. Postel-Vinay, and J.-M. Robin (2006): "Wage Bargaining with On-the-job Search: Theory and Evidence," Econometrica, 74, 323-365.

Carling, K., B. Holmlund, and A. Vejsiu (2001): "Do Benefit Cuts Boost Job Findings," Economic Journal, 111, 766-790.

Coles, M., and A. Masters (2004): "Duration-Dependent Unemployment Insurance Payments and Equilibrium Unemployment," Economica, 71, 83-97.

(2007): "Re-entitlement effects with duration-dependent unemployment insurance in a stochastic matching equilibrium," Journal of Economic Dynamics and Control, 31, 2879-2898.

Coles, M. G., and A. Muthoo (2003): "Bargaining in a non-stationary environment," Journal of Economic Theory, 109, 70-89.

Coles, M. G., and R. Wright (1998): "A Dynamic Equilibrium Model of Search, Bargaining, and Money," Journal of Economic Literature, 78, 32-54.

Corradi, G., J. Janssen, and R. Manca (2004): "Numerical Treatment of Homogeneous Semi-Markov Processes in Transient Case - a Straightforward Approach," Methodology and Computing in Applied Probability, 6, 233 - 246.

Diamond, P. A. (1982): "Aggregate Demand Management in Search Equilibrium," Journal of Political Economy, 90, 881-94.

Eckstein, Z., and G. van den Berg (2007): "Empirical Labor Search: A Survey," Journal of Econometrics, 136, 531-564.

Eckstein, Z., and K. I. Wolpin (1995): "Duration to First Job and the Return to Schooling: Estimates from a Search-Matching Model," Review of Economic Studies, 62, 263-286.

Fahrmeir, L., H. L. Kaufmann, and F. Ost (1981): Stochastische Prozesse. Eine Einführung in Theorie und Anwendungen. Hanser Fachbuchverlag.

Ferrall, C. (1997): "Unemployment Insurance Eligibility and the School-to-Work Transition in Canada and the United States," Journal of Business \& Economic Statistics, 15, 115-129.

Flinn, C. (2006): "Minimum Wage Effects on Labor Market Outcomes under Search, Matching, and Endogenous Contact Rates," Econometrica, 74, 1013-1062.

Flinn, C., and J. Heckman (1982): "New methods for analyzing structural models of labor force dynamics," Journal of Econometrics, 18, 115-168.

Fredriksson, P., and B. Holmlund (2001): "Optimal Unemployment Insurance in Search Equilibrium," Journal of Labor Economics, 19, 370-399.

Hall, R. E., and P. R. Milgrom (2008): "The Limited Influence of Unemployment on the Wage Bargain," American Economic Review, June 2008. 
Heckman, J., and G. Borjas (1980): "Does Unemployment Cause Future Unemployment? Definitions, Questions and Answers from a Continuous Time Model of Heterogeneity and State Dependence," Economica, 47, 247-283.

Heckman, J., and B. Singer (1984): "A Method of Minimizing Distributional Assumptions in Economertic Models for Duration Data," Econometrica, 52, 271-320.

Hopenhayn, H. A., and J. P. Nicolini (1997): "Optimal Unemployment Insurance," Journal of Political Economy, 105, 412-438.

Hosios, A. J. (1990): "On the Efficiency of Matching Models and Related Models of Search and Unemployment," Review of Economic Studies, 57, 279-298.

Hujer, R., and H. Schneider (1989): "The Analysis of Labour Market Mobility Using Panel Data," European Economic Review, 33, 530-536.

Kiefer, N. M., and G. R. Neumann (1981): "Individual Effects in a Nonlinear Model: Explicit Treatment of Heterogeneity in the Empirical Job-Search-Model," Econometrica, 49, 965 -979 .

Kulkarni, V. G. (1995): Modeling and Analysis of Stochastic Systems. Chapman \& Hall.

Lancaster, T. (1990): The Econometric Analysis of Transition Data. Cambridge University Press.

Launov, A., I. Schumm, and K. Wälde (2009): "Efficiency and Distributional Effects of Labour Market Reforms (Hartz IV)," mimeo, University of Glasgow.

Ljungqvist, L., and T. J. Sargent (1998): “The European Unemployment Dilemma," Journal of Political Economy, 106(3), 514-550.

(2007a): "Understanding European unemployment with a representative family," Journal of Monetary Economics, 54, 2180-2204.

(2007b): "Understanding European unemployment with matching and search-island models," Journal of Monetary Economics, 54, 2139-2179.

Moffitt, R., and W. Nicholson (1982): "The Effect of Unemployment Insurance on Unemployment: The Case of Federal Supplemental Benefits," The Review of Economics and Statistics, 64, 1-11.

Mongrain, S., and J. Roberts (2005): "Unemployment Insurance and Experience Rating: Insurance versus Efficiency," International Economic Review, 46, 1303-1319.

Mortensen, D. (1977): "Unemployment Insurance and Job Search Decisions," Industrial and Labor Relations Review, 30, 505-517.

Mortensen, D. T. (1982): "Property Rights and Efficiency in Mating, Racing, and Related Games," American Economic Review, 72, 968-79. 
Mortensen, D. T., and C. A. Pissarides (1999): "New developments in models of search in the labor market," in Handbook of Labor Economics, ed. by O. Ashenfelter, and D. Card, chap. 39, pp. 2567-2627. Elsevier.

Moscarini, G. (2005): "Job Matching and the Wage Distribution," Econometrica, 73(2), $481-516$.

OECD (2004): Benefits and Wages. OECD, Paris.

(2007): Benefits and Wages. "Daten und Grafiken", downloaded from www.oecd.org/de/benefitsandwages on 12 June 2008.

Pissarides, C. A. (1985): "Short-run Equilibrium Dynamics of Unemployment Vacancies, and Real Wages," American Economic Review, 75, 676-90.

Postel-Vinay, F., and J.-M. Robin (2002): "Equilibrium Wage Dispersion with Worker and Employer Heterogeneity," Econometrica, 70, 2295-2350.

Pyke, R. (1961a): "Markov Renewal Processes: Definitions and Preliminary Properties," The Annals of Mathematical Statistics, 32, 1231-1242.

_ (1961b): "Markov Renewal Processes with Finitely Many States," The Annals of Mathematical Statistics, 32, 1243-1259.

Rogerson, R., R. Shimer, and R. Wright (2005): "Search-Theoretic Models of the Labor Market: A Survey," Journal of Economic Literature, 43, 959-988.

Ross, S. M. (1996): Stochastic processes, 2nd edition. Academic Press, San Diego.

Røed, K., and T. Zhang (2003): "Does Unemployment Compensation Affect Unemployment Duration?," Economic Journal, 113, 190-206.

Schumm, I. (2009): "Semi-Markov processes in labour market theory," mimeo, University of Würzburg.

Shavell, S., and L. Weiss (1979): "The Optimal Payment of Unemployment Insurance Benefits over Time," Journal of Political Economy, 87, 1347-1362.

Shimer, R., and I. Werning (2007): "Reservation Wages and Unemployment Insurance," Quarterly Journal of Economics, 122(3), 1145-1185.

Tanner, M., and W. H. Wong (1983): "The Estimation of the Hazard Function from Randomly Censored Data by the Kernel Method," Annals of Statistics, 11, 989-993.

_ (1984): "Data-Based Nonparametric Estimation of the Hazard Function with Applications to Model Diagnostics and Exploratory Analysis," Journal of the American Statistical Association, 79, 174-182.

van den Berg, G., B. van der Klaauw, and J. van Ours (2004): "Punitive Sanctions and the Transition from Welfare to Work," Journal of Labor Economics, 22, 211-241. 
van den Berg, G. J. (1990): "Nonstationarity in Job Search Theory," Review of Economic Studies, 57, 255-277.

van den Berg, G. J., and G. Ridder (1998): "An Empirical Equilibrium Search Model of the Labor Market," Econometrica, 66, 1183-1221.

van den Berg, G. J., and J. C. van Ours (1996): "Unemployment Dynamics and Duration Dependence," Journal of Labor Economics, 14, 100-125.

(1999): "Duration Dependence and Heterogeneity in French Youth Unemployment Durations," Journal of Population Economics, 12, 273-285.

Vishvanath, T. (1989): "Job Search, Stigma Effect and Escape Rate from Unemployment," Journal of Labor Economics, 7, 487-502. 